\title{
Origin of Oligodendrocytes in the Subventricular Zone of the Adult Brain
}

\author{
Bénédicte Menn, ${ }^{1}$ Jose Manuel Garcia-Verdugo, ${ }^{2}$ Cynthia Yaschine, ${ }^{1}$ Oscar Gonzalez-Perez, ${ }^{1}$ David Rowitch, ${ }^{3}$ and \\ Arturo Alvarez-Buylla ${ }^{1}$ \\ ${ }^{1}$ Department of Neurosurgery and Developmental and Stem Cell Biology Program, University of California at San Francisco, San Francisco, California \\ 94143, ${ }^{2}$ University of Valencia, 46010 Valencia, Spain, and ${ }^{3}$ Department of Pediatric Oncology, Dana-Farber Cancer Institute, Harvard Medical School, \\ Boston, Massachusetts 02115
}

Glial fibrillary acidic protein (GFAP)-positive astrocytes (type B cells) in the subventricular zone (SVZ) generate large numbers of new neurons in the adult brain. SVZ stem cells can also generate oligodendrocytes in vitro, but it is not known whether these adult primary progenitors generate oligodendrocytes in vivo. Myelin repair and oligodendrocyte formation in the adult brain is instead associated with glial-restricted progenitors cells, known as oligodendrocyte progenitor cells (OPCs). Here we show that type B cells also generate a small number of nonmyelinating NG2-positive OPCs and mature myelinating oligodendrocytes. Some type B cells and a small subpopulation of actively dividing type C (transit-amplifying) cells expressed oligodendrocyte lineage transcription factor 2 (0lig2), suggesting that oligodendrocyte differentiation in the SVZ begins early in the lineage. Olig2-positive, polysialylated neural cell adhesion moleculepositive, PDGF receptor $\alpha$-positive, and $\beta$-tubulin-negative cells originating in the SVZ migrated into corpus callosum, striatum, and fimbria fornix to differentiate into the NG2-positive nonmyelinating and mature myelinating oligodendrocytes. Furthermore, primary clonal cultures of type B cells gave rise to oligodendrocytes alone or oligodendrocytes and neurons. Importantly, the number of oligodendrocytes derived from type B cells in vivo increased fourfold after a demyelinating lesion in corpus callosum, indicating that SVZ astrocytes participate in myelin repair in the adult brain. Our work identifies SVZ type B cells as progenitors of oligodendrocytes in normal and injured adult brain.

Key words: adult oligodendrogenesis; CNS stem cells; oligodendrocyte progenitors; SVZ astrocyte; myelin repair; Olig2

\section{Introduction}

Oligodendrocytes are the myelinating cells of the CNS and are essential for proper brain function. Most oligodendrocytes develop during embryogenesis and early postnatal life from restricted periventricular germinal regions (Warf et al., 1991; Pringle and Richardson, 1993; Timsit et al., 1995; Olivier et al., 2001; Rowitch, 2004; Vallstedt et al., 2004). Forebrain oligodendrocytes originate first from progenitors in the embryonic ventral telencephalon (Spassky et al., 1998; Woodruff et al., 2001). This early wave of oligodendrocytes is transitory and superseded by oligodendrocytes originating latter in development from dorsal telencephalic sources (Kessaris et al., 2006). From their sites of origins,

\footnotetext{
Received 0ct. 24, 2005; revised June 19, 2006; accepted June 21, 2006.

This work was supported by National Institutes of Health Grant HD 32116 and by The Brain Tumor Society. B.M. was supported by Association pour la Recherche contre le Cancer and Institut National de la Santé et de la Recherche Médicale fellowships. J.M.G.-V. was supported by La Caixa Foundation. We are grateful to E. Holland for the Gtv-a mice. We thank C. Stiles and J. Trotter for providing us, respectively, with the 0lig2 and the ascending neuron AN2 antibodies. We also thank M. Goetz for providing the RCAS-GFP construct. We thankN. Spassky, A. D. Tramontin, and Erica Jackson for helpful discussion and critical reading of this manuscript.

Correspondence should be addressed to Arturo Alvarez-Buylla, Department of Neurosurgery and Developmental and Stem Cell Biology Program, University of California at San Francisco, Box 0525, San Francisco, CA 94143. E-mail: abuylla@stemcell.ucsf.edu.

0. Gonzalez-Perez's present address: Neuroscience Department, Centro Universitario de la Salud, Universidad de Guadalajara, Jalisco 44340, México.

D01:10.1523/JNEUROSCI.1299-06.2006

Copyright $\odot 2006$ Society for Neuroscience $\quad 0270-6474 / 06 / 267907-12 \$ 15.00 / 0$
}

oligodendrocyte progenitors (OPCs) migrate to colonize the gray and white brain matter (Thomas et al., 2000; Qi et al., 2002). Many OPCs, characterized by the expression of NG2 chondroitin sulfate, divide to form mature myelinating oligodendrocytes, but others linger as slowly dividing immature cells widely distributed within the adult brain (Polito and Reynolds, 2005). Interestingly, oligodendrocytes continue to be produced in the adult brain (Blakemore, 1972; Prineas and Connell, 1979; Kaplan and Hinds, 1980; McCarthy and Leblond, 1988), and these cells participate in myelin repair (Gensert and Goldman, 1997; Chari and Blakemore, 2002). Here we investigated whether neural stem cells present in the subventricular zone (SVZ) of the adult brain generate new OPCs and mature oligodendrocytes and whether these stem cells contribute to the repair of myelin.

In neonates, retroviral lineage studies have shown that the SVZ is an important source of astrocytes, oligodendrocytes, and neurons (Levison and Goldman, 1993; Luskin, 1993). In the adult, the SVZ continues to generate neurons that reach the olfactory bulb (OB) through the rostral migratory stream (RMS) (Lois and Alvarez-Buylla, 1994). Several lines of evidence indicate that oligodendrocyte progenitors also persist in the adult SVZ. Adult neural stem cells grown from the adult SVZ as neurospheres can generate oligodendrocytes (Morshead et al., 1994; Gritti et al., 1996; Weiss et al., 1996; Doetsch et al., 1999; Pluchino et al., 2003). Importantly, adult SVZ progenitors generate new 
oligodendrocytes in vivo after demyelinating lesions of the corpus callosum (CC) (Nait-Oumesmar et al., 1999; Picard-Riera et al., 2002) or after seizures (Parent et al., 2006). The primary progenitors for new oligodendrocytes born in the adult SVZ have not been identified.

Glial fibrillary acidic protein (GFAP)-expressing SVZ astrocytes serve as primary precursors of new neurons (Doetsch et al., 1999). These astrocytes, or SVZ type B cells, generate transit amplifying type $\mathrm{C}$ cells that express transcription factors Dlx2 (distal-less homeobox 2) (Doetsch et al., 2002) and Mash1 (mammalian achaete-schute homolog 1) (Parras et al., 2004). Here, we show that type B cells at different rostrocaudal levels of the SVZ generate not only neurons but also oligodendrocytes. Type B cells give rise to migrating young oligodendrocytes that differentiate into immature $\mathrm{NG} 2$-positive $\left(\mathrm{NG}_{2}{ }^{+}\right)$cells that continue to divide locally or mature into myelinating cells. Furthermore, primary cultures of single SVZ type B cells gave rise to oligodendrocytes alone or oligodendrocytes and neurons. This work identifies cells and regions in the SVZ giving rise to new oligodendrocytes in the adult brain.

\section{Materials and Methods}

Animal care and tissue processing. Gtv-a (Holland and Varmus, 1998) or CD-1 (Charles River Laboratories, Wilmington, MA) mice were housed in the University of California, San Francisco Animal Care Facility and were maintained in accordance with the University of California Committee on Animal Research guidelines. For surgical procedures, adult mice were deeply anesthetized with $60 \mathrm{mg} / \mathrm{kg}$ body weight of pentobarbital (Nembutal) injected intraperitoneally and maintained with $5 \%$ halothane when necessary. For tissue preparation, adult animals received an overdose of Nembutal (200 $\mathrm{mg} / \mathrm{kg}$ body weight) before transcardial perfusion. For light microscopy, mice were perfused with $3 \%$ paraformaldehyde (PFA) in $0.1 \mathrm{~m}$ phosphate buffer (PB). Brains were postfixed overnight at $4^{\circ} \mathrm{C}$ in the same fixative. Whole mounts of the lateral wall of the lateral ventricle were dissected as described previously (Doetsch and Alvarez-Buylla, 1996), or 50- $\mu$ m-thick horizontal brain sections were cut with a vibratome. For electron microscopy, adult mice were killed by intracardial perfusion with $2 \%$ PFA and $0.8 \%$ glutaraldehyde in $0.1 \mathrm{M}$ PB for alkaline phosphatase (AP) staining, 2\% PFA and $0.5 \%$ glutaraldehyde for immunocytochemistry (ICC), or 2\% PFA and $2.5 \%$ glutaraldehyde for conventional electron microscopy (EM). Brains were postfixed in the same fixative overnight at $4^{\circ} \mathrm{C}$, cut horizontally at 100 $\mu \mathrm{m}$, and processed for EM as described previously (Doetsch et al., 1997). Briefly, for AP staining and ICC, tissue samples were washed in maleate buffer and postfixed in $1 \%$ osmium tetroxide in $0.1 \mathrm{M} P B$ for $3 \mathrm{~h}$, postfixed in $2 \%$ osmium for $2 \mathrm{~h}$, rinsed, dehydrated, and embedded in Araldite. For conventional EM, sections were postfixed in $2 \%$ osmium for $2 \mathrm{~h}$ instead. Semithin sections, $1.5 \mu \mathrm{m}$ thick, were cut with a diamond knife and stained with $1 \%$ toluidine blue. For the identification of individual cell types, ultrathin $(0.05 \mu \mathrm{m})$ sections were cut with a diamond knife, stained with lead citrate, and examined under a Jeol (Peabody, MA) 100CX electron microscope.

Cell cultures. For coculture experiments, the protocol previously established in the laboratory (Lim and Alvarez-Buylla, 1999) was followed except that DMEM/F-12/B27 medium was used instead of Neurobasal. For single-cell experiments, the GFAP promoter $\left(\mathrm{GFAP}_{\mathrm{p}}\right)$-green fluorescent protein (GFP) adenovirus (100 nl) (Doetsch et al., 1999) was first injected in vivo into the SVZ of adult CD-1 mice $1.5 \mathrm{~d}$ before the dissection. Adult SVZ or striatal cells were then freshly dissociated, purified through a $22 \%$ Percoll gradient, and plated on top of a postnatal day 3 (P3) mouse cortical astrocyte monolayer in DMEM/F-12/B27 medium either at $50,000 \mathrm{cells} / \mathrm{cm}^{2}$ or as a single cell after selection and isolation using a MoFlo fluorescence-activated cell sorter (DakoCytomation, Carpinteria, CA). Double cells were excluded using pulse width and integrated signal. Cultures were fixed at 1,3 , or $5 \mathrm{~d}$ in vitro (div) with $3 \%$ PFA for 20 min at room temperature and washed three times with PBS.

For cell blots, SVZ cells were dissected from adult CD-1 mice incubated in papain (14 U/ml; Worthington, Lakewood, NJ) for $30 \mathrm{~min}$ at $37^{\circ} \mathrm{C}$, dissociated to single-cell suspension, and resuspended in DMEM/ F-12 for $2 \mathrm{~h}$ before fixation with 3\% PFA.

Immunocytochemistry. After blocking in PBS containing 10\% of normal goat serum for $2 \mathrm{~h}$ at room temperature, cells or tissue sections were incubated with primary antibodies overnight at $4^{\circ} \mathrm{C}$ in the blocking solution. The following primary antibodies were used: mouse monoclonal anti- $\beta$-tubulin (Tuj1) (1:500; Berkeley Antibody Company, Berkeley, CA), anti- $\mathrm{O}_{4}$ (1:50; Chemicon, Temecula, CA), anti-GFAP (1:500; Chemicon), anti-polysialylated neural cell adhesion molecule (PSANCAM) (1:400; AbCys, Annecy, France), chicken monoclonal anti-GFP (1:1000; Aves Lab,Tigard, OR), rabbit polyclonal anti-oligodendrocyte lineage transcription factor 2 (Olig2) (1:5000) (Ligon et al., 2004), antiplatelet-derived growth factor receptor $\alpha$ (PDGFR $\alpha$ ) (1:50; Santa Cruz Biotechnology, Santa Cruz, CA), for identification of NG2 we used AN2 (1:1000) (Niehaus et al., 1999) and anti-NG2 (Chemicon) anti-myelin basic protein (MBP) (1:100; Chemicon), and anti-CNPase (1:500; Chemicon). For fluorescent ICC, cells, tissue sections, or whole mounts were washed in PBS, incubated with the appropriate secondary antibodies [all cyan at 1:400 (Jackson ImmunoResearch, West Grove, PA); all Alexa at 1:1000 (Invitrogen, Carlsbad, CA)] in blocking solution for $2 \mathrm{~h}$ at room temperature [cyanine 2 (Cy2) anti-mouse IgG, $\mathrm{Cy} 3$ anti-mouse IgM, Cy3 anti-rabbit IgG, Alexa-488 anti-chicken IgG, or Alexa-564 antirabbit IgG], and washed in PBS. For preembedding Olig2 ICC, sections were washed in $\mathrm{PB}$, incubated in blocking solution with a biotinylated anti-rabbit (1:400; Jackson ImmunoResearch) overnight at $4^{\circ} \mathrm{C}$, incubated in ABC peroxidase kit (Vector Laboratories, Burlingame, $\mathrm{CA}$ ) for $2 \mathrm{~h}$, and revealed with $0.02 \%$ diaminobenzidine and $0.01 \% \mathrm{H}_{2} \mathrm{O}_{2}$. Controls in which primary antibodies were omitted resulted in no detectable staining.

Retroviral injections. We used a $\beta$ - actin $_{\mathrm{p}}-\mathrm{GFP}$ retrovirus (200 nl) (Carleton et al., 2003) to label all dividing cells in the SVZ and CC. Before injection, $\beta$-actin $_{\mathrm{p}}-\mathrm{GFP}$ virus was mixed with polybrene $(8 \mu \mathrm{g} / \mathrm{ml}$; Sigma, St. Louis, MO). Two types of replication competent avian retroviruses (RCASs) (100 nl injection volume) were used to label dividing GFAP-expressing SVZ astrocytes in P60-P120 Gtv-a mice (Holland and Varmus, 1998): RCAS-AP (Holland and Varmus, 1998), which encodes AP, and RCAS-GFP (a gift from M. Goetz, GSF, Institut für Stamzellforschung, Neuherberg, Germany), which encodes GFP. RCAS-AP labels thin processes allowing morphological characterization of cells under bright field. This virus, however, labeled fewer cells than the RCASGFP, and AP staining is not compatible with most ICC techniques. For ICC costaining, we therefore used the RCAS-GFP retrovirus. A GFAP GFP adenovirus (100 nl) (Doetsch et al., 1999) was used to labeled SVZ astrocytes for cell sorting and in vitro clonal analysis. Injections were made stereotaxically at the following coordinates (anteroposterior relative to bregma, mediolateral, and dorsoventral from surface of the brain): for SVZ, as shown in Table 1; for CC, $(1,1.8,1.25)$; or as described in Results. Brains were processed for AP staining as described below. As a control for specificity, a mixture of RCAS-AP and adenovirus $\beta$-actin ${ }_{\mathrm{p}}$ GFP (a gift from Dr. C. Lois, Massachusetts Institute of Technology, Cambridge, MA) (10:1) was coinjected bilaterally into the CC of two adult Gtv-a mice.

Demyelinating lesion. Demyelination was induced by injecting lysolecithin (LPC) into corpus callosum as described previously (Gensert and Goldman, 1997; Nait-Oumesmar et al., 1999). To label the SVZ astrocytes and their progeny, RCAS-GFP was injected into the anterior SVZ of adult P60-P120 GFAP-Tv-a mice. Two days later, $0.5 \mu \mathrm{l}$ of $1 \%$ LPC (Sigma) dissolved in $0.9 \% \mathrm{NaCl}$ was ipsilaterally injected into the corpus callosum.

Immunohistochemistry with a rabbit anti-degraded MBP antibody (Chemicon) was performed to detect the demyelinating lesions and verify the extent of demyelination. The control vehicle group received $0.5 \mu \mathrm{l}$ of $0.9 \% \mathrm{NaCl}$. All animals ( $n=3$ per group) were killed $30 \mathrm{~d}$ after lysolecithin or vehicle injection.

Alkaline phosphatase staining. Endogenous AP activity was inactivated by heating the sections in a $65^{\circ} \mathrm{C}$ PBS bath for $30 \mathrm{~min}$. The sections were then washed in AP detection buffer (in mM: 100 Tris- $\mathrm{HCl}, \mathrm{pH} 9.5,100$ $\mathrm{NaCl}$, and $5 \mathrm{MgCl} 2$ ) for 10 min and incubated in AP buffer containing nitroblue tetrazolium chloride $(10 \mu \mathrm{l} / \mathrm{ml}$; Boehringer Mannheim, 
$\beta$ actin $_{\mathrm{p}}-\mathrm{GFP} / \mathrm{21}$ days
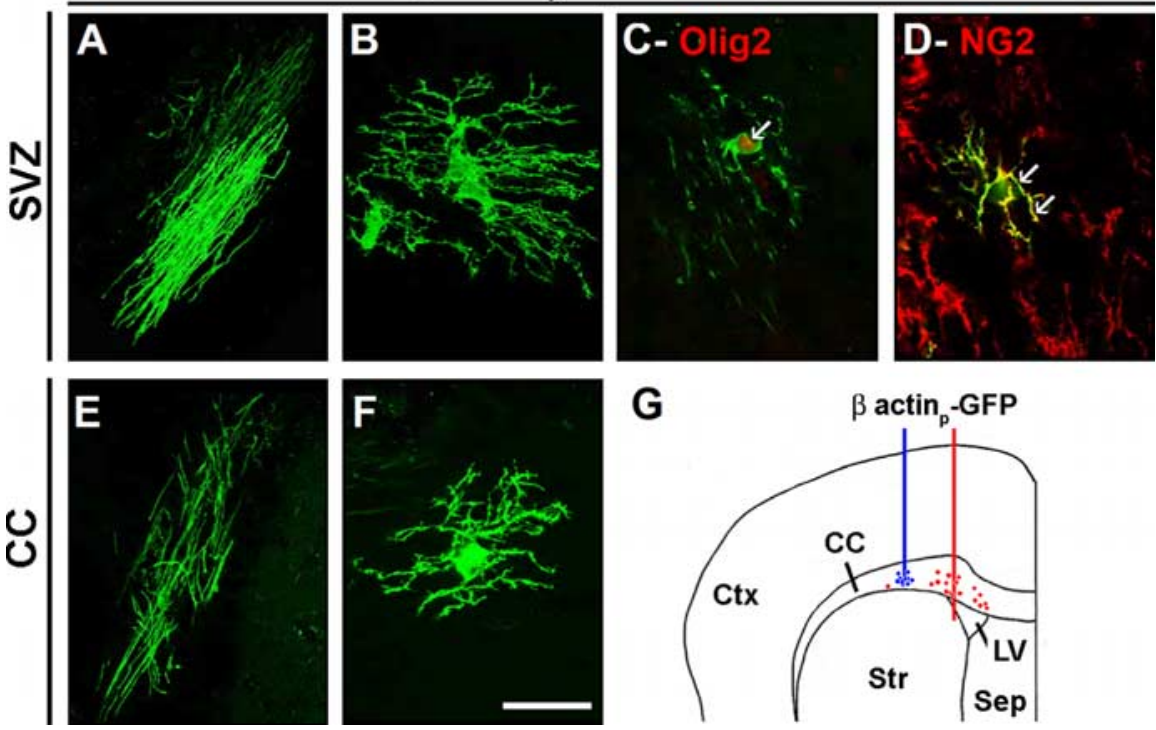

Figure 1. Oligodendrocyte progenitors exist in the SVZand in the CC of the adult mouse brain. Replication-incompetent murine $\beta$-actin $_{\mathrm{p}}$ GFP virus was injected into the SVZ $(\boldsymbol{A}-\boldsymbol{D})$ or the $C(\boldsymbol{E}, \boldsymbol{F})$ of adult CD-1 mice. At $21 \mathrm{~d}$ after injection, GFP-labeled mature myelinating $(\boldsymbol{A}, \boldsymbol{E})$ and nonmyelinating $(\boldsymbol{B}-\boldsymbol{D}, \boldsymbol{F})$ oligodendrocytes were identified in the CC. $\boldsymbol{C}, \boldsymbol{D}$, Double immunofluorescence with GFP (green) and Olig2 ( $\boldsymbol{C}$, red) or NG2 (D, red). Note that highly branched GFP ${ }^{+}$nonmyelinating oligodendrocytes express both markers. G, Schematic representation of an adult mouse brain hemisphere showing the location of GFP-labeled cells in the

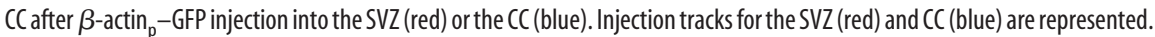
Note that GFP-labeled cells are widely dispersed in the adult CC after SVZ retroviral injection in contrast to those generated after injection into the CC. Ctx, Cortex; LV, lateral ventricle; Sep, septum; Str, striatum. Scale bar, $60 \mu \mathrm{m}$.

Mannheim, Germany) and 5-bromo-4-chloro-3-indolyl phosphate (2 $\mu \mathrm{l} / \mathrm{ml}$; Boehringer Mannheim, Germany) for 3-5 h at room temperature. The reaction was stopped in fresh PBS containing 20 mм EDTA.

\section{Results}

Adult SVZ and CC contain proliferating

oligodendrocyte progenitors

To analyze the progeny of adult SVZ cells, we stereotaxically in-

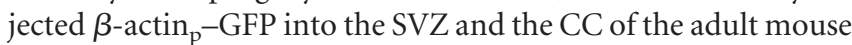
brain. Three weeks after injection of this retrovirus into the SVZ, GFP-labeled granular and periglomerular neurons were observed in the $\mathrm{OB}$ of the injected hemispheres (data not shown), confirming that SVZ progenitors had been initially infected. GFP-labeled cells with the typical morphology of oligodendrocytes were also found dispersed in the CC. Because GFP labeling fills the cell processes, we were able to identify two subtypes of oligodendrocytes based on morphology: mature myelinating oligodendrocytes (Fig. 1A) (Levison and Goldman, 1993; Butt, 2004) and highly branched cells with the typical morphology of parenchymal OPCs, also known as nonmyelinating oligodendrocytes (Fig. 1 B) (Butt, 2004). These $\mathrm{GFP}^{+}$nonmyelinating oligodendrocytes expressed Olig2 (Fig. 1C) and NG2 (Fig. 1D). Proliferating oligodendrocyte progenitors are present in the adult brain parenchyma, including the CC (Polito and Reynolds, 2005). Consistently, injection of retrovirus encoding $\beta$-actin $_{\mathrm{p}}-\mathrm{GFP}$ into the CC resulted in labeled myelinating (Fig. $1 E$ ) and nonmyelinating oligodendrocytes (Fig. $1 F$ ) $21 \mathrm{~d}$ later. However, in contrast to the SVZ injections, the $\beta$-actin $_{\mathrm{p}}-\mathrm{GFP}$ retroviral injections into the CC did not label cells that migrate to the $\mathrm{OB}$. Interestingly, $\mathrm{GFP}^{+}$oligodendrocytes derived from the SVZ injections migrated as much as $550 \mu \mathrm{m}$ from the injection site. In contrast, labeled oligodendrocytes after CC injections were found no more than $50 \mu \mathrm{m}$ from the injection site (Fig. 1G). Results indicate that dividing cells in both the SVZ and the CC generate oligodendrocytes, but progenitors in the CC give rise to oligodendrocytes that differentiate relatively close to the injection site, whereas oligodendrocytes derived from SVZ progenitors disperse throughout the CC and the neighboring striatum.

\section{SVZ astrocytes give rise to} oligodendrocytes in the adult mouse brain

SVZ type B cells, which have characteristics of astrocytes and express GFAP, have been identified as primary precursors of new neurons in the adult mouse brain (Doetsch et al., 1999). We next tested whether such SVZ astrocytes also generate oligodendrocytes in vivo. For this, we used transgenic Gtv-a mice expressing the avian leucosis virus receptor subgroup A (Tv-a) under the control of the GFAP promoter (Holland and Varmus, 1998). Infection of P60-P120 Gtv-a mice with RCAS-AP results in specific labeling of dividing $\mathrm{GFAP}^{+}$cells (Holland and Varmus, 1998) and their progeny (Doetsch et al., 1999). We stereotaxically injected RCAS-AP and RCAS-GFP retrovirus into the anterior region of the SVZ of adult Gtv-a mice. The AP encoding RCAS virus allowed morphological identification and Golgi-like reconstruction of labeled cells, whereas RCAS virus encoding GFP allowed double-immunohistochemical labeling. Three weeks after RCAS virus injections into SVZ, AP ${ }^{+}$or $\mathrm{GFP}^{+}$astrocytes were observed close to the injection site in the SVZ, as well as labeled neurons in the OB (Doetsch et al., 1999). In all of these animals $(n=18)$, we also observed $\mathrm{AP}^{+}$or $\mathrm{GFP}^{+}$ cells in the CC and the white matter tracks in the striatum and fimbria fornix that displayed the characteristic morphology of nonmyelinating (Fig. 2A) and myelinating (Fig. 2D, G,J) oligodendrocytes. RCAS-labeled oligodendrocytes were not observed in cortex. We used EM to further identify the oligodendrocytes derived from labeled SVZ astrocytes. AP-labeled cells were first identified as nonmyelinating (Fig. 2A) or myelinating (Fig. 2D) oligodendrocytes in 50 - $\mu \mathrm{m}$-thick sections using light microscopy. Serial $1.5 \mu \mathrm{m}$ plastic sections of these same cells were reembedded and resectioned to $100 \mathrm{~nm}$ sections and analyzed by EM. Nonmyelinating oligodendrocytes were relatively large with an electron-lucent nucleus and a light cytoplasm with many polyribosomes (Fig. 2 B,C). Myelinating cells had darker cytoplasm with prominent Golgi apparatus and a short endoplasmic reticulum. They also had an electron-dense nucleus with heavy clumps of chromatin that formed a prominent layer beneath the nuclear envelope (Fig. 2E,F). These are typical ultrastructural characteristics of nonmyelinating and myelinating oligodendrocytes (Peters et al., 1991). To confirm the identity of SVZ type B progeny in the $\mathrm{CC}$, we stained tissue sections of brains infected with RCAS-GFP virus with several markers of mature oligodendrocytes. GFP-labeled cells expressed the CNS myelin protein CNPase (Fig. 2G-I) and MBP (Fig. $2 J-L$ ).

We next tested whether proliferating astrocytes also serve as 
oligodendrocyte progenitors outside the SVZ. We injected RCAS-AP into the CC through the cortex but outside the SVZ $(n=4)$. To confirm the location of the injection, we coinjected an adenovirus encoding GFP $\left(\beta\right.$-actin $\left._{\mathrm{p}}-\mathrm{GFP}\right)$ that infects all cells. Twenty-one days after injection, $\mathrm{GFP}^{+}$cells were observed in the CC (data not shown), but in none of the hemispheres injected did we observe APlabeled oligodendrocytes. Similar results were observed after injection of the RCAS virus into different regions, including cortex $(n=4)$, medial and lateral striatum $(n=4)$, and lateral CC $(n=2)$. Occasionally, we found labeled astrocytes close to the injection track, but in none of these mice did we observe labeled oligodendrocytes. These findings indicated that $\mathrm{GFAP}^{+}$oligodendrocyte precursors are in the SVZ.

Oligodendrocytes are generated from SVZ type B cells at different rostrocaudal levels of the adult mouse SVZ

The above experiments targeted the SVZ adjacent to the anterior horn of the lateral ventricle. To investigate whether astrocytes at different rostrocaudal locations in the SVZ generate oligodendrocytes, we used the RCAS-AP retrovirus injected at different rostrocaudal coordinates to target the SVZ, as indicated in Table 1. Animals were killed $21 \mathrm{~d}$ after injection; their brains were serially sectioned, processed for AP staining, and $\mathrm{AP}^{+}$myelinating oligodendrocytes as well as differentiated $\mathrm{AP}^{+} \mathrm{OB}$ neurons were counted. The number of mature oligodendrocytes produced from SVZ astrocytes at different rostrocaudal locations was very similar (Table 1). The number of oligodendrocytes formed was consistently lower compared with the number of neurons that migrate into and differentiate in the $\mathrm{OB}$. This ratio, however, changed depending on the injection site; a proportionally higher number of $\mathrm{OB}$ neurons were produced from type B cells labeled in the anterior part of the SVZ compared with caudal $\mathrm{SVZ}$. $\mathrm{AP}^{+}$neurons migrated tangentially to the $\mathrm{OB}$ from all the different rostrocaudal SVZ locations tested as described previously (Doetsch and Alvarez-Buylla, 1996). In contrast, AP-labeled oligodendrocytes remained at approximately the same rostrocaudal level of the injection site but migrated laterally or dorsally into the CC, the fornix, and the fiber tracks of the striatum. We did not observe migration of oligodendrocyte precursors into the cortex, the hippocampus (HP), or the OB. These results indicate that both neurons and oligodendrocytes are formed from dividing SVZ astrocytes located at different rostrocaudal levels of the lateral ventricu-

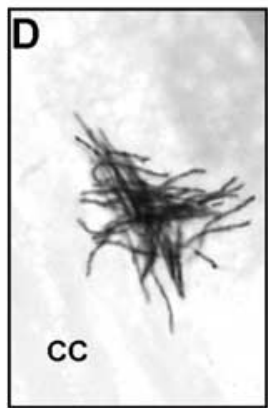

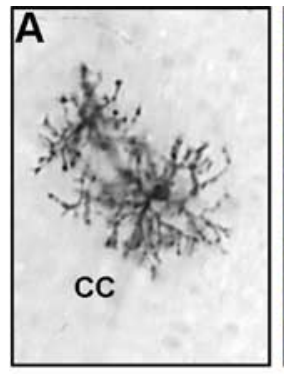
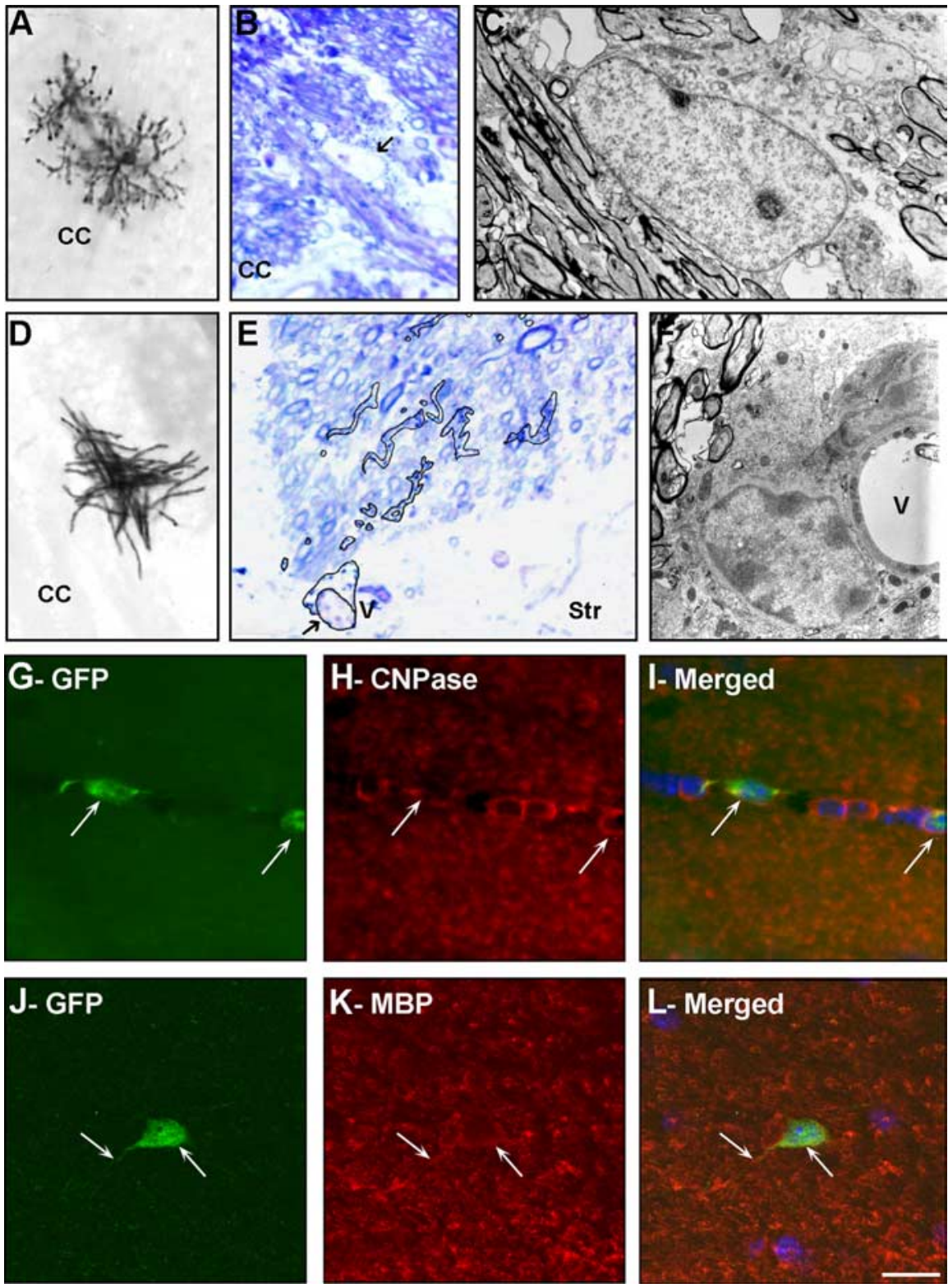

Figure 2. SVZ astrocytes give rise to oligodendrocytes in the adult mouse brain. RCAS-AP $(\boldsymbol{A}-\boldsymbol{F})$ or RCAS-GFP $(\mathbf{G}-\boldsymbol{L})$ retroviruses were injected into the SVZ of adult Gtv-a mice, and the progeny of the infected SVZ astrocytes was analyzed $21 \mathrm{~d}$ after injection using light $(\boldsymbol{A}, \boldsymbol{B}, \boldsymbol{D}, \boldsymbol{E})$, confocal $(\boldsymbol{G}-\boldsymbol{L})$, and electron $(\boldsymbol{C}, \boldsymbol{F})$ microscopy. $\boldsymbol{A}-\boldsymbol{F}$, Several AP-labeled cells were identified in the $C(\boldsymbol{A}-\boldsymbol{D})$ and in the striatum $(\boldsymbol{E}, \boldsymbol{F})$ : highly branched cells presenting typical morphology of nonmyelinating $(\boldsymbol{A}-\boldsymbol{C})$ and myelinating $(\boldsymbol{D}-\boldsymbol{F})$ oligodendrocytes. Characteristics of $\mathrm{AP}^{+}$nonmyelinating oligodendrocytes $(\boldsymbol{B}, \boldsymbol{C})$ and $\mathrm{AP}^{+}$mature myelinating oligodendrocytes $(\boldsymbol{E}, \boldsymbol{F})$ were determined at the ultrastructural level. $\boldsymbol{B}, \boldsymbol{E}, \mathrm{AP}$-staining in 1.5 - $\mu \mathrm{m}$-thick semithin sections counterstained with toluidine blue. Arrows indicate the nucleus of the cells analyzed at the electron microscopic level. $\ln E, A P^{+}$ cell body and processes were traced on top of the picture. $C, F$, Electron micrograph of $\mathrm{AP}^{+}{ }^{+}$cells. Note the different ultrastructure and typical nuclear heterochromatin in myelinating oligodendrocytes compared with that of the nonmyelinating one. $\mathbf{G}-\boldsymbol{L}$, Double immunofluorescence for GFP $(\boldsymbol{G}, J)$ and the oligodendrocyte markers CNPase $(\boldsymbol{H})$ or MBP $(\boldsymbol{K})$ of cells in the CC. Merged field shows combined immunostaining for GFP and CNPase $(\boldsymbol{I})$ or MBP $(\boldsymbol{L})$. Arrows indicated SVZ-generated cells in the C(-expressing markers of mature oligodendrocytes. Str, Striatum; $V$, blood vessel. Scale bar: $A, D, 80 \mu \mathrm{m} ; \boldsymbol{B}, \boldsymbol{E}, 7 \mu \mathrm{m} ; \boldsymbol{C}, \boldsymbol{F}, 2 \mu \mathrm{m} ; \mathbf{G}-\mathbf{L}, 20 \mu \mathrm{m}$.

lar wall. The paths of migration for these two cell types are very different. Young neurons migrate tangentially into the OB, whereas oligodendrocytes appear to migrate away from the SVZ and remain at rostrocaudal levels similar to their site of origin.

\section{Identification of migrating oligodendroglial progenitors}

In addition to the nonmyelinating and myelinating oligodendrocytes derived from our viral injections described above, we also 
Table 1. Cell types produced after RCAS-AP infection at different rostrocaudal SVZ levels

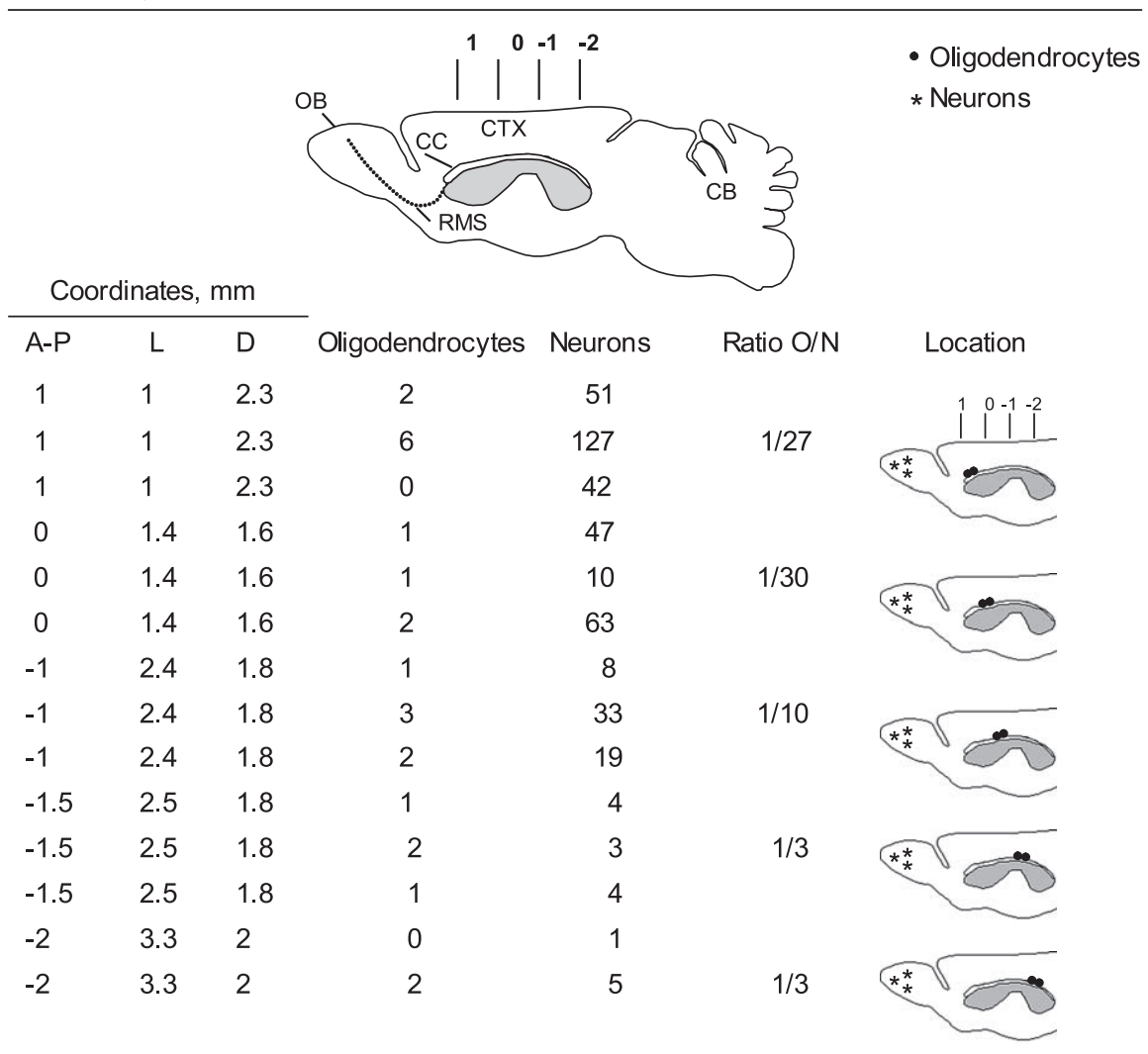

This table indicates the number of $\mathrm{AP}^{+}$mature meylinating oligodendrocytes and differentiated neurons found in the adult mouse brain 3 weeks after retroviral infection of astrocytes located at different rostrocaudal levels of the SVZ. The schematic at the top illustrates the lateral wall of the lateral ventricle and its coordinates relative to bregma. Bilateral injections of RCAS-AP were performed in adult Gtv-a mice $\left(n=5\right.$ for each coordinate). AP ${ }^{+}$cells were counted in 1 of every 4 horizontal $50 \mathrm{~mm}$ sections, through the whole brain. Ratio $0 / \mathrm{N}$ indicates the number of oligodendocytes versus neurons. Note a similar number of oligodendrocytes produced regardless of the original injection coordinates in contrast to neurons. Schematic representation of $\mathrm{AP}^{+}$cell distribution after retroviral infection of $S V Z$ astrocytes at different locations is indicated on the right side of the table. Note that neurons were always found in the $0 B$ while oligodendrocytes were located at a rostrocaudal level similar to that of the injection site. CB, Cerebellum; CC, corpus callosum; CTX, cortex; OB, olfactory bulb; RMS, rostral migratory stream.

noticed the presence of elongated cells that resemble migrating cells. We first studied the distribution and antigenic properties of these putative migrating cells in the CC in whole-mount preparations of the SVZ and CC as described previously (Doetsch and Alvarez-Buylla, 1996). For these dissections, paraventricular segments facing the CC were dissected together with the lateral wall of the lateral ventricle. These paraventricular regions correspond to regions of the lateral ventricle that have become obliterated as both walls of the ventricle fuse during development. The most extensive paraventricular region, the subcallosal zone (SCZ), is located between the HP and the CC (Seri et al., 2006). Many elongated cells labeled by PSA-NCAM were present in this region (Fig. 3A). Similar cells were also present close to the SVZ and in more anterior CC. In contrast to the chains of PSA-NCAM ${ }^{+}$cells described previously in the SVZ and RMS (Doetsch and AlvarezBuylla, 1996; Peretto et al., 1997), PSA-NCAM ${ }^{+}$cells in the CC and the SCZ above the HP were not arranged in chains, but the majority appeared to be migrating as individual cells. They had an elongated cell body, with a leading process tipped by a growth cone, and occasionally had a trailing process (Fig. 3B). Unlike $\mathrm{PSA}^{-N_{C A M}}{ }^{+}$young neurons, which also express neuronspecific Tuj1 (Fig. 3C-E) (Doetsch and Alvarez-Buylla, 1996), $\mathrm{PSA}-N C A M^{+}$cells in the CC were negative for Tuj1 (Fig. $3 F-H$ ). $\mathrm{PSA}_{\mathrm{NCAM}}{ }^{+} / \mathrm{Tuj}^{1-}$ cells in the CC may correspond to migrating oligodendrocyte precursors (Ben-Hur et al., 1998). Consistently, PSA-NCAM ${ }^{+}$cells in the CC were also positive for PDGFR $\alpha$ (Fig. $3 I-K)$ and the NG2 chondroitin sulfate proteogly- can (Fig. $3 L-N$ ), which have been shown to be expressed in oligodendrocyte progenitors (Pringle and Richardson, 1993; Nishiyama et al., 1996; Polito and Reynolds, 2005). We next investigated whether these putative migrating cells arise from SVZ astrocytes. RCAS-AP (Fig. 3O) or $\beta$ - actin $_{\mathrm{p}}$-GFP (Fig. 3P,Q) retroviruses were injected into the adult SVZ, and animals were killed 1 and $4 \mathrm{~d}$ later. In these animals, $\mathrm{AP}^{+}$or $\mathrm{GFP}^{+}$elongated cells were present in the SVZ and the CC. They stained for Olig2 (Fig. 3Q).

It was remarkable how similar the morphology of $\mathrm{AP}^{+}$migrating cells was in the SVZ and CC. We confirmed this observation using EM and preembedding immunocytochemistry for PSA-NCAM. PSA$\mathrm{NCAM}^{+}$cells first identified in $2-\mu \mathrm{m}$ thick sections (Fig. 3R) were resectioned and analyzed at the electron microscopic level (Fig. 3S). The cells had ultrastructural features of migrating cells: an elongated body and a leading process with a centrosome at its base (Fig. 3S). These elongated cells had a very different ultrastructure from that of astrocytes and oligodendrocytes in the CC. They had scant cytoplasm, numerous ribosomes, and no intermediate filaments. These characteristics are similar to those of young neurons migrating in the RMS and SVZ (Luskin, 1993; Lois et al., 1996; Wichterle et al., 1997). However, unlike young neurons in the SVZ and RMS, putative migrating young oligodendrocytes in the CC were not ensheathed by astrocytes. In contrast, they were tightly associated with myelinated and unmyelinated axons.

\section{A subpopulation of SVZ type B and C cells express Olig2}

The above results allowed us to identify oligodendrocytes at different stages of maturation after exiting the SVZ (supplemental data 2, available at www.jneurosci.org as supplemental material). To identify the cells in the SVZ that give rise to these migrating oligodendrocyte progenitors, we used antibodies that label oligodendrocytes at different stages of maturation (Baumann and Pham-Dinh, 2001). Olig2 is a transcription factor necessary for the development of oligodendrocyte lineage, receptor interacting protein (Rip) is expressed by nonmyelinating oligodendrocyte progenitors, and MBP and myelin/oligodendrocyte glycoprotein (MOG) are markers of mature myelinating oligodendrocytes. No labeling was observed in the adult mouse SVZ for Rip, MBP, and MOG (data not shown), indicating that mature oligodendrocytes were not present in this germinal region. As described previously (Hack et al., 2005), Olig2-expressing cells were observed in the SVZ. They were identified as an actively dividing cell population (supplemental data 1, available at www.jneurosci.org as supplemental material) (Hack et al., 2005) often organized as small clusters (Fig. 4A), suggesting that they may correspond to type $\mathrm{C}$ cells (Doetsch et al., 1997; Parras et al., 2004). Interestingly, only one or two cells expressed Olig2 within the clusters (Fig. 4A,E). To determine to which cell type Olig ${ }^{+}$SVZ cells correspond, we studied 34 Olig ${ }^{+}$cells with the electron microscope. Of these 
cells, 16 displayed typical characteristics of type $\mathrm{C}$ cells (Fig. $4 A, B$ ): abundant mitochondria, short endoplasmic reticulum and large Golgi apparatus, few microtubules, and intermediate filaments (Fig. $4 B$, inset). Nine of the 34 studied cells had an elongated morphology, and these cells were found to contact myelinated axons (Fig. 4C,D). These cells probably correspond to early migrating oligodendrocyte precursors.

Interestingly, the other 15 Olig2expressing cells analyzed at the electron microscopic level had bundles of intermediate filaments and light cytoplasm typical of SVZ astrocytes (Fig. 4F). To confirm this observation at the light microscopic level, we performed double ICC in mouse brain tissue using the anti-Olig2 and the anti-GFAP antibodies. A small fraction of Olig2 ${ }^{+}$nuclei were clearly surrounded by $\mathrm{GFAP}^{+}$staining, suggesting colocalization (Fig. 4G). However, this could be attributable to $\mathrm{GFAP}^{+}$processes from neighboring cells wrapping around Olig2 ${ }^{+}$cells. To clearly colocalize the label in individual cells, we freshly dissociated cells from adult SVZ and stained them for Olig2 and GFAP (Fig. $4 H$ ). We observed that a small fraction $(3.3 \pm 0.4 \%$, mean \pm SEM; $n=4$ independent dissection) of Olig ${ }^{+}$cells were also $\mathrm{GFAP}^{+}$. In addition, we found that $10.0 \pm 0.7 \%$ (mean \pm SEM; $n=3$ independent dissection) of SVZ Olig2 ${ }^{+}$ cells also expressed $\mathrm{S} 100 \beta$ (Fig. $4 I$ ), which is considered a marker for astrocytes by some authors (Reeves et al., 1994; Nishiyama et al., 2002) but has also been suggested to be expressed in cells in the oligodendrocyte lineage (Jennings et al., 2002; Deloume et al., 2004).

Higher number of oligodendrocytes are derived from SVZ type B cells after a demyelinating lesion

Previous studies suggested that progenitor cells in the SVZ contribute to the repair of demyelinating lesions (Nait-Oumesmar et al., 1999; Picard-Riera et al., 2002). We next investigated whether oligodendrocytes derived from SVZ astrocytes contribute to the repair of white matter tracts after a demyelinating lesion. SVZ astrocytes were first labeled by injection of RCASGFP into the anterior SVZ of adult GFAPTv-a mice. Two days later, lysolecithin or vehicle was ipsilaterally injected into the CC. Thirty days after demyelination, a 4.3fold increase in the number of $\mathrm{GFP}^{+}$cells in the corpus callosum of lysolecithininjected hemispheres was observed (650 \pm 35 cells; $n=3$ ) compared with the control vehicle group (149 \pm 58 cells; $n=3 ; p<$
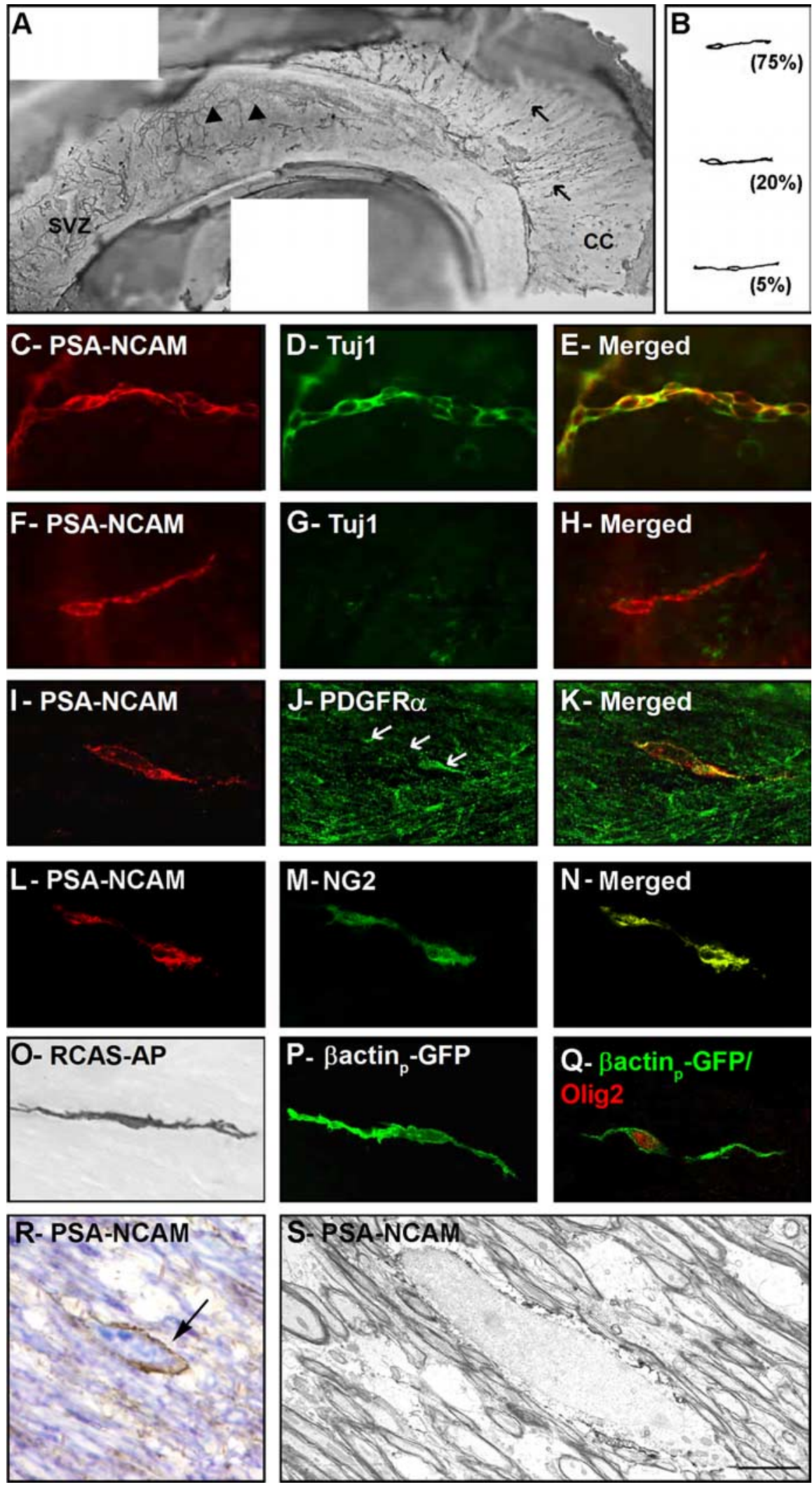

Figure 3. PSA-NCAM-immunopositive cells migrate tangentially within the CC. $A$, Photomontage of PSA-NCAM immunostaining of whole-mount preparation of the lateral wall of the lateral ventricle and the CC. Dorsal is up, and rostral is left. Filled arrowheads show chains of PSA-NCAM ${ }^{+}$cells migrating on the lateral wall of the lateral ventricle. Arrows show PSA-NCAM ${ }^{+}$ cells migrating within the CC. B, Camera lucida drawing of PSA-NCAM ${ }^{+}$cells observed in the CC. These cells are unipolar, with a short leading process, or bipolar. Percentages of cells displaying each morphology are indicated. $\boldsymbol{C}-\boldsymbol{N}$, Double immunofluorescence for PSA-NCAM $(\boldsymbol{C}, \boldsymbol{F}, \boldsymbol{I}, \boldsymbol{L})$ and Tuj1 $(\boldsymbol{D}, \boldsymbol{G}), \operatorname{PDGFR} \alpha(\boldsymbol{J})$, or NG2 $(\boldsymbol{M})$ of cells localized on the lateral wall of the lateral ventricle $(\boldsymbol{C}-\boldsymbol{E})$ and on the $C(\boldsymbol{F}-\boldsymbol{N})$. Merged field shows combined immunostaining for PSA-NCAM and . (Figure legend continues.) 

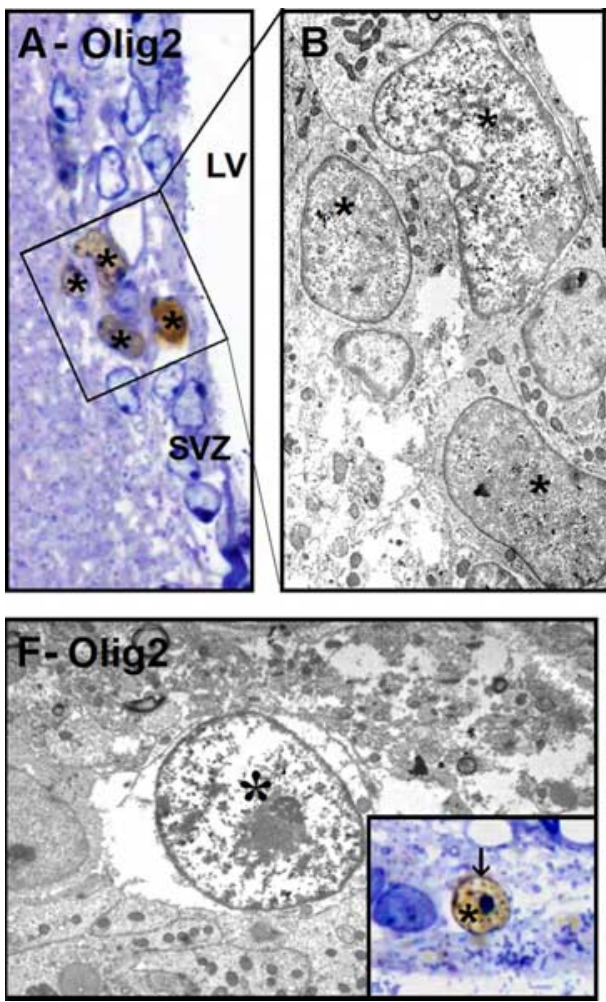
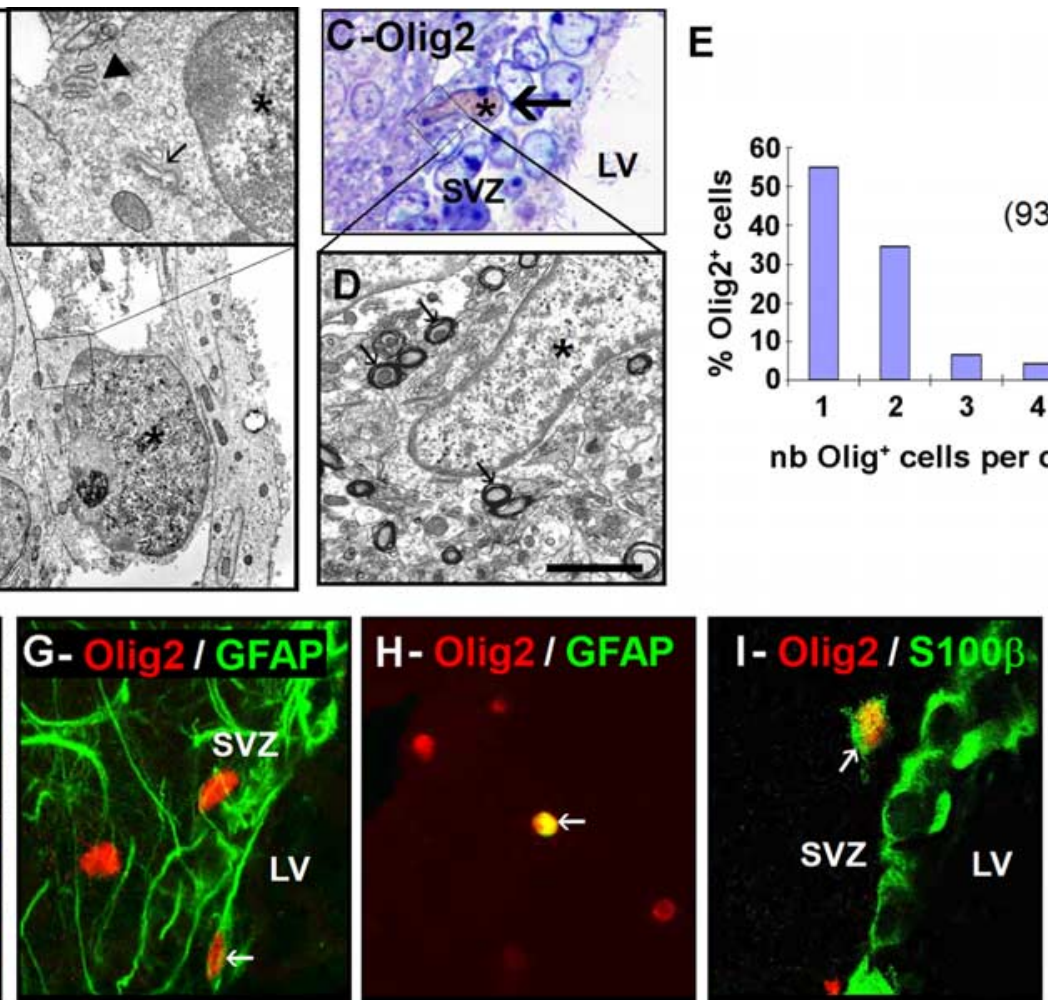

Figure 4. The basic helix-loop-helix transcription factor Olig2 is expressed by a subpopulation of immature transit-amplifying type C cells and by some SVZ astrocytes. Electron microscopic characterization of 0 lig2 ${ }^{+}$cells in the adult mouse SVZ. $A, C$, Inset in $\boldsymbol{F}$, Olig2 staining in plastic $1.5-\mu \mathrm{m}$-thick semithin section counterstained with toluidine blue. Arrows or asterisks indicate Olig2-labeled cells analyzed at the electron microscopic level. $\boldsymbol{B}, \boldsymbol{D}, \boldsymbol{F}$, Electron micrograph of these cells. Asterisks show the nucleus. $\boldsymbol{A}-\boldsymbol{D}, 0$ lig $2^{+}$cells display the ultrastructural characteristics of type $C$ cells: medium dark cytoplasm, numerous mitochondria, large Golgi apparatus (arrows in inset in $\boldsymbol{B}$ ), and short endoplasmic reticulum (arrowheads in inset in $\boldsymbol{B}$ ). Note that some 0 lig2 ${ }^{+}$cells have an elongated morphology (C). The cytoplasm of Olig2 ${ }^{+}$cell is often in contact with myelinated axons (arrows in $\left.\mathbf{D}\right) . \mathbf{E}, 0$ lig2 ${ }^{+}$cells were grouped in small clusters in the SVZ. Ninety-three Olig2 ${ }^{+}$cells were analyzed in $1.5-\mu \mathrm{m}$-thick sections. The diagram indicates the percentage of Olig2 ${ }^{+}$cells that were either alone or associated in small groups of two to five cells. nb, Number of. $\boldsymbol{F}$-I, 0 lig2 ${ }^{+}$SVZ cells can also present ultrastructural characteristics of type BSVZastrocytes that appear to be acquiring some characteristics of type (cells. $\boldsymbol{F}$, Electron micrograph of such a cell. $\mathbf{G}-\mathbf{I}$, This observation was confirmed by performing double immunofluorescence for 0lig2 (red) and GFAP (green, $\mathbf{G , H}$ ) or S100 $\beta$ (green, I) performed on coronal sections of adult mouse brain ( $\mathbf{G}, \boldsymbol{I}$ ) or on freshly dissociated adult SVZ cells $(\boldsymbol{H})$. Arrows indicate cells expressing both markers. LV, Lateral ventricle. Scale bar: $\boldsymbol{A}, \boldsymbol{C}$, inset in $\boldsymbol{F}, 10 \mu \mathrm{m} ; \boldsymbol{B}, \boldsymbol{D}, \boldsymbol{F}, 3 \mu \mathrm{m} ;$ inset in $\boldsymbol{B}, 1 \mu \mathrm{m} ; \boldsymbol{G}, \boldsymbol{I}, 20 \mu \mathrm{m} ; \boldsymbol{H}, 40 \mu \mathrm{m}$.

0.01) (Fig. 5A,B). Moreover, these $\mathrm{GFP}^{+}$cells appear to be concentrated within and around the demyelination site (Fig. $5 B$ ). $\mathrm{GFP}^{+}$cells in the lesion site had the morphology of both mature and immature oligodendrocytes (Fig. 5C). To further characterize these $\mathrm{GFP}^{+}$cells, we coimmunostained these sections with antibodies for NG2, S100 $\beta$, and Olig2. Similar proportions of cells stained with these markers were observed in the lesioned and vehicle injected groups: $69.8 \pm 11 \% \mathrm{~S} 100 \beta^{+} / \mathrm{GFP}^{+}$in the lysolecithin versus $62.8 \pm 5 \%$ in the control; $42.8 \pm 10 \%$ Olig $^{+}$/ $\mathrm{GFP}^{+}$in the lysolecithin versus $35.1 \pm 12 \%$ in control; and $48.5 \pm 6 \% \mathrm{NG}^{+} / \mathrm{GFP}^{+}$in the lysolecithin versus $40.2 \pm 8 \%$ in control. We also analyzed an additional control group $(n=3)$ that received RCAS-GFP in the SVZ but in which injection of saline into the corpus callosum was omitted. The number of $\mathrm{GFP}^{+}$cells and proportion of these cells expressing the different oligodendrocyte markers was similar between the saline-injected and these control animals that only received the virus injection (data not shown). These results suggest that, after the lesion, the increased number of cells derived from SVZ astrocytes had similar characteristics as those normally produced in the control animals. $\mathrm{GFP}^{+}$cells in the CC of lesioned brains expressed CNPase, a marker for CNS myelin protein (Fig. $5 D$ ). The precise number of CNPase-positive cells was difficult to quantify because of the diffuse pattern of staining of this marker. However, clear examples of double-labeled cells were observed, indicating that a subpopulation of the cells produced after the lesion mature into myelinating oligodendrocytes.

\section{SVZ astrocytes generate oligodendrocytes and neurons in vitro}

SVZ cells propagated as neurospheres can differentiate into both oligodendrocytes and neurons in vitro (Morshead et al., 1994; Gritti et al., 1996; Weiss et al., 1996; Imura et al., 2003). However, neurospheres are exposed to growth factors, which may modify the normal differentiation program of neural progenitors (Doetsch et al., 2002; Gabay et al., 2003; Santa-Olalla et al., 2003; Hack et al., 2004; Reynolds and Rietze, 2005). To determine whether SVZ progenitors could give rise to oligodendrocytes in vitro, we plated freshly dissociated adult SVZ cells onto a
(Figure legend continued.) Tuj1 $(\boldsymbol{E}, \boldsymbol{H}), \operatorname{PDGFR} \alpha(\boldsymbol{K})$, or NG2 $(\boldsymbol{N})$. PSA-NCAM ${ }^{+}$cells migrating tangentially as chains expressed the neuronal marker Tuj $1(\boldsymbol{C}-\boldsymbol{E})$. In contrast, PSA-NCAM ${ }^{+}$cells present at the surface of the $C($ did not colabel with Tuj $1(\boldsymbol{F}-\boldsymbol{H})$ but with the oligodendrocyte markers PDGFR $\alpha(\boldsymbol{I}-\boldsymbol{K})$ and NG2 $(\boldsymbol{L}-\boldsymbol{N}) . \mathbf{0}-\mathbf{Q}$, Putative migrating cells located in the $C($ and labeled after injection of RCAS-AP $(\mathbf{O})$ or $\beta$-actin - GFP $(\boldsymbol{P}, \mathbf{Q})$ into the adult mouse SVZ. $\mathbf{Q}$, Double immunofluorescence for GFP (green) and Olig2 (red) of a bipolar cell. $\boldsymbol{R}$, $\boldsymbol{S}$, Electron microscopic characterization of a PSA-NCAM-positive cell in the CC. $\boldsymbol{R}$, PSA-NCAM staining in toluidine blue-stained $1.5-\mu \mathrm{m}$-thick semithin section. Arrow indicates the PSA-NCAM ${ }^{+}$cell analyzed at the electron microscopic level. $S$, Electron micrograph of this PSA-NCAM ${ }^{+}$cell. Note that its elongated nucleus contains lax chromatin. Scale bar: $\boldsymbol{A}, 400 \mathrm{~nm} ; \boldsymbol{C}-\boldsymbol{E}, 60 \mu \mathrm{m} ; \boldsymbol{F}-\mathbf{Q}, 50 \mu \mathrm{m} ; \boldsymbol{R}, 5 \mu \mathrm{m} ; \boldsymbol{S}, 2 \mu \mathrm{m}$.

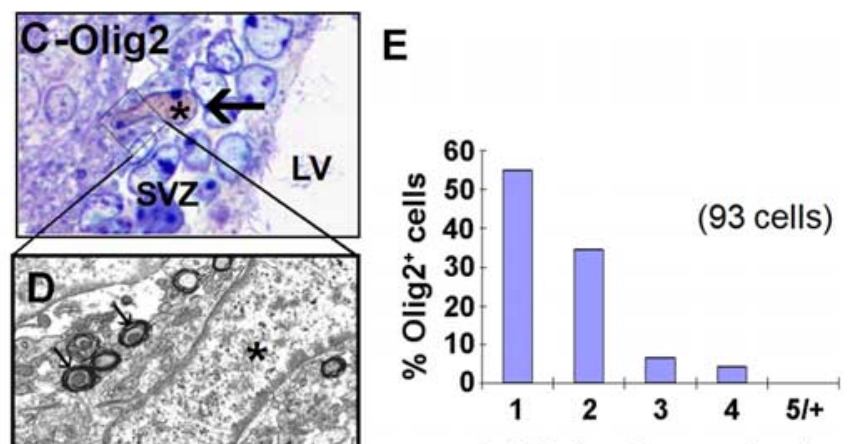

nb Olig ${ }^{+}$cells per cluster

西


confluent monolayer of cortical astrocytes using a modified protocol (see Materials and Methods) used previously to study neuronal differentiation (Lim and Alvarez-Buylla, 1999). We show here that this culture conditions results in robust oligodendrocyte formation from SVZ precursors. One day after plating, surviving SVZ cells were present as single cells. By 3 div, small clusters of three to five cells appeared (Fig. 6A). At this time, double immunofluorescence for Tuj1 and the $\mathrm{O}_{4}$ antibodies revealed the presence of cells expressing the neuronal or oligodendroglial markers within the same cluster (Fig. $6 B-D$ ). Five days after plating, Tuj ${ }^{+}$cells (Fig. $6 E$ ) and $\mathrm{O}_{4}{ }^{+}$cells (Fig. 6F) displayed the morphology of neurons and oligodendrocytes, respectively. $\mathrm{O}_{4}{ }^{+}$cells also expressed Olig2 and NG2 (data not shown). Because oligodendrocyte progenitors are present within the striatum (some of which is dissected with the SVZ), it was possible that our cultures were contaminated with parenchymal OPCs. To control for this possibility, cells from the striatum adjacent to the SVZ of adult animals were plated on cortical astrocytes as described above. Under these culture conditions, neither neurons nor oligodendrocytes were observed in the cultures at 5 div. Finally, oligodendrocytes did not arise from cortical astrocytes without plating SVZ progenitors on top. These observations indicate that SVZ cells are able to generate both neurons and oligodendrocytes in our culture conditions, yet it was possible that oligodendrocytes and neurons were derived from two separate progenitor subpopulations.

To address this question, we examined the potential of single SVZ astrocytes plated onto the monolayer of cortical astrocytes. To isolate SVZ astrocytes, we used a GFAP $\mathrm{p}_{\mathrm{p}} \mathrm{GFP}$ adenovirus that encodes the GFP marker under the transcriptional control of the GFAP promoter (Doetsch et al., 1999) (Fig. 6G). SVZ astrocytes were first labeled in vivo by injecting the adenovirus into the SVZ of adult CD-1 mice. Thirty six hours after injection, $\mathrm{GFP}^{+}$cells were isolated by fluorescence-activated cell sorting (FACS) (Fig. 6H) and plated as single cells on the monolayer of cortical astrocytes. Five days later, the cultures were fixed and immunostained with $\mathrm{O}_{4}$ and Tuj 1 antibodies (Fig. 6I). Twenty-six percent of plated cells gave rise to colonies. Of these, $11.5 \%$ generated both neurons and oligodendrocytes. Interestingly, the majority of colonies $(80.3 \%)$ contained only oligodendrocytes but not neurons. This finding confirms that oligodendrocytes can be derived from GFAP-expressing SVZ cells and that a subpopulation of these cells can generate both neurons and oligodendrocytes.

\section{Discussion}

This study shows that adult SVZ astrocytes (type B cells) serve as primary progenitors of new oligodendrocytes in normal and in- jured brain. Results suggest that SVZ type B cells, through intermediate Olig $2^{+}$transit-amplifying cells (type C cells), give rise to young migrating oligodendrocytes that move out of the SVZ into the CC, neighboring striatum, and fimbria fornix to differentiate into nonmyelinating and myelinating oligodendrocytes. Compared with the large number of new neurons born in the SVZ, few oligodendrocytes are normally produced from adult SVZ type B cells. This may be related to the slow turnover of oligodendrocytes in adult brain (McCarthy and Leblond, 1988). Interestingly, however, the number of oligodendrocytes derived from SVZ type $B$ cells was increased after a demyelinating lesion. In these conditions, SVZ-generated oligodendrocytes express markers of myelin, suggesting that they contribute to the remyelination process. This is consistent with the suggestion that, in addition to the parenchymal OPC progenitors (Fancy et al., 2004), SVZ progenitors contribute to the repair of myelinated tracks (NaitOumesmar et al., 1999; Picard-Riera et al., 2002; Petratos et al., 2004).

Labeling dividing cells with $\beta$-actin p $_{\mathrm{p}}$ GFP retrovirus targeted to either the SVZ or the CC resulted in labeled oligodendrocytes close to the injection site. In contrast, labeling with a retrovirus that infects GFAP-expressing cells results in labeled oligodendrocytes only when the injection is targeted to the SVZ. This suggests that oligodendrocytes are derived from two sources of adult dividing cells, GFAP-expressing SVZ cells and non-GFAP dividing 

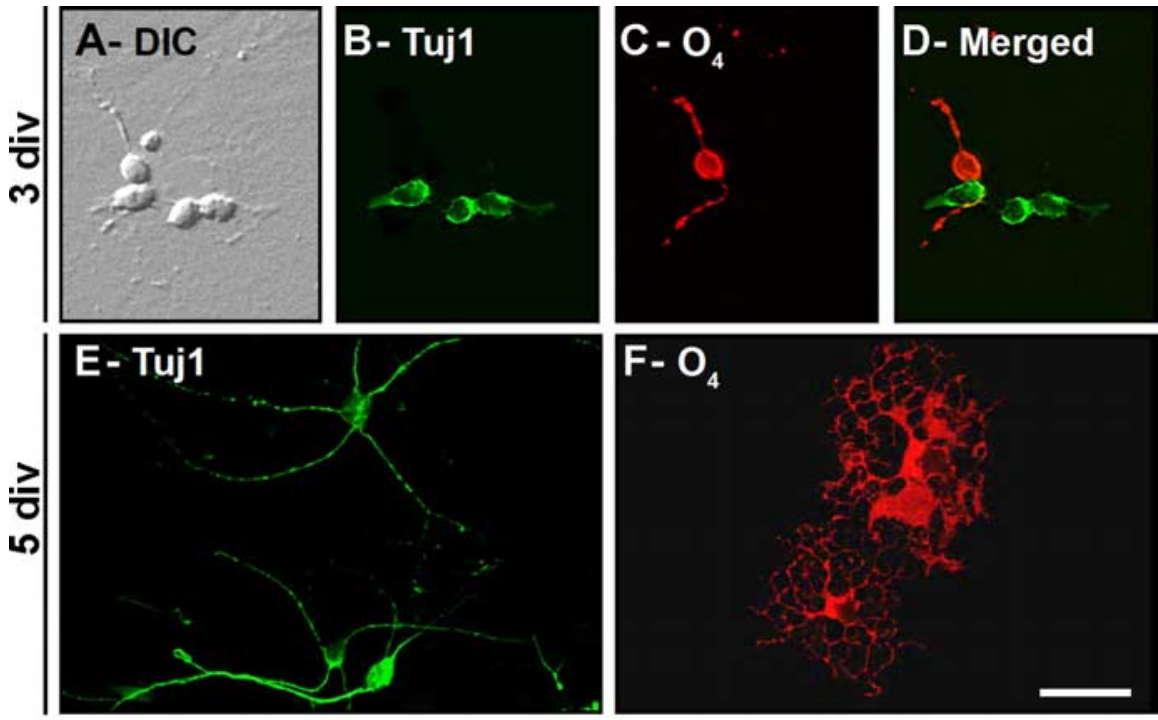

G

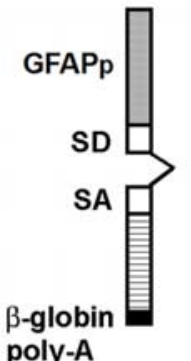

H poly-A

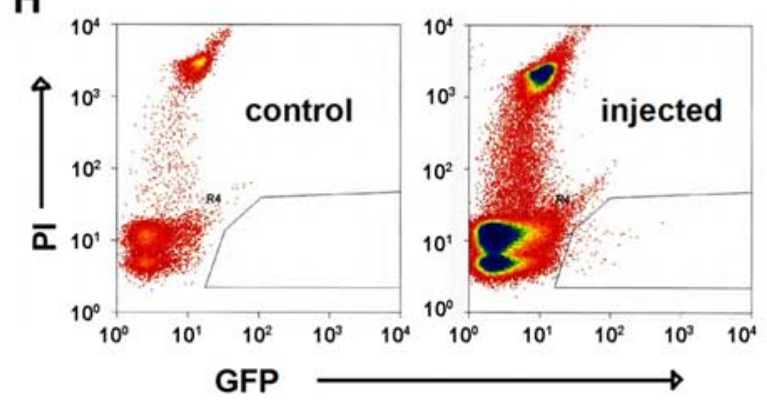

I

\begin{tabular}{lccccc} 
& No. single & \multicolumn{5}{c}{ No. colonies at 5 div } \\
\cline { 3 - 6 } & cell plated & total & $\mathrm{O}_{4}^{+}$ & Tuj1 $^{+}$ & $\mathrm{O}_{4}{ }^{+}+$Tuj1+ \\
\hline Exp 1 & 93 & 45 & 39 & 2 & 4 \\
Exp 2 & 50 & 6 & 4 & 1 & 1 \\
Exp 3 & 90 & 10 & 6 & 2 & 2 \\
\hline Total & 233 & 61 & 49 & 5 & 7
\end{tabular}

Figure 6. SVZ astrocytes produce oligodendrocytes in vitro, and some produce both neurons and oligodendrocytes. $\boldsymbol{A}-\boldsymbol{F}$, Ten thousand SVZ cells isolated from adult CD-1 mice were allowed to differentiate on top of an astrocytic monolayer for $3 \operatorname{div}(\boldsymbol{A}-\boldsymbol{D})$ and $5 \operatorname{div}(\boldsymbol{E}, \boldsymbol{F}) . \boldsymbol{A}-\boldsymbol{D}$, At 3 div, clusters derived from adult SVZ precursor cells are mixed colonies which contain both $\mathrm{O}_{4}{ }^{+}$and $\mathrm{Tuj}^{+}{ }^{+}$cells. $\boldsymbol{E}, \boldsymbol{F}, \mathrm{At} 5 \mathrm{div}$, Tuj ${ }^{+}(\boldsymbol{E})$ and $\mathrm{O}_{4}{ }^{+}(\boldsymbol{F})$ cells present typical morphologies of differentiated neurons and oligodendrocytes, respectively. $\boldsymbol{A}$, Differential interference contrast (DIC) image of a typical colony. $\boldsymbol{B}, \boldsymbol{E}$, Immunoreactivity for the neuronal marker Tuj1. $C, F$, Immunoreactivity for the oligodendroglial marker $\mathrm{O}_{4} . \boldsymbol{D}$, Merged field showing combined immunostaining for Tuj 1 and $\mathrm{O}_{4}$. $\mathbf{G}-\mathbf{I}$, Single SVZ astrocytes give rise to both neurons and oligodendrocytes in vitro. Adult SVZ astrocytes were specifically labeled in vivo or in vitro with an adenovirus GFAP - GFP. G, Schematic showing the GFAP promoter reporter construct used for the adenoviral vector. $\boldsymbol{H}, \boldsymbol{I}$, Single GFP ${ }^{+}$SVZ astrocytes were purified by FACS, plated on top of an astrocytic monolayer, and grown in culture for 5 div. $\boldsymbol{H}$, Density plots showing gates for selecting SVZ astrocytes [GFP and propidium iodide (PI)]. The right plot corresponds to the sorting of SVZ cells isolated at $1.5 \mathrm{~d}$ after injection of the adenovirus GFAP - GFP; the left plot is a control non-injected animal. $I$, The number of GFP ${ }^{+}$cells initially plated is indicated for each experiment ( 3 independent cultures). The total number of colonies that arose from these cells is presented. These colonies contained only $\mathrm{O}_{4}{ }^{+}$, only Tuj ${ }^{+}{ }^{+}$or both $\mathrm{O}_{4}{ }^{+}$and Tuj $1{ }^{+}$cells. Note that 61 of the 233 single GFP ${ }^{+}$SVZ cells initially plated gave rise to colonies. Among them, seven generated mixed colonies. Scale bar: $\boldsymbol{A}-\boldsymbol{F}, 10 \mu \mathrm{m}$. SD, Splice donor; SA, splice acceptor.

cells outside the SVZ. Interestingly, the progeny of cells that divide locally within the CC do not appear to migrate far from the site of injection, which is consistent with previous observations showing that the progeny of parenchymal OPCs do not migrate

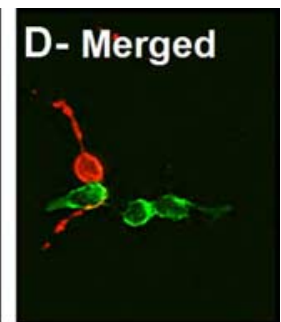

extensively (Gensert and Goldman, 1997). This is in contrast with the progeny derived from SVZ GFAP-expressing cells that can migrate long distances.

Classical models of cell lineages in the CNS propose that neural stem cells produce two separate pools of progenitors that generate either neurons or astrocytes and oligodendrocytes (Raff et al., 1983; Rao, 1999). However, committed glial precursors, like the optic nerve O-2A progenitor, can be manipulated to also generate neurons (Kondo and Raff, 2000). Recent evidence in vivo indicates that neurons and some glial cells are closely related in development and originate from common progenitors in ways that do not fit classical models that separate the neuronal and glial lineages (Williams et al., 1991; Richardson et al., 2000; He et al., 2001; Lu et al., 2002; Zhou and Anderson, 2002; Lui and Rao, 2004; Rowitch, 2004). Consistently, our data suggest that adult SVZ GFAP ${ }^{+}$cells, which have been shown to function as neuronal precursors, can also give rise to oligodendrocytes. A small subpopulation of single astrocytes isolated in vitro gave rise to both neurons and oligodendrocytes. However, we do not know whether single progenitors in vivo have this dual potential or whether separate pools of type $B$ cells that generate neurons or oligodendrocytes coexist in the SVZ.

Our results suggest Olig2 expression and function in the adult forebrain is associated to the oligodendrocyte lineage compared with the spinal cord, in which both neuron and oligodendrocyte development depends on Olig2. By using light and electron microscopy, we confirmed that Olig2, a transcription factor that plays an essential role in the generation of oligodendrocytes during embryogenesis (Zhou et al., 2000; Lu et al., 2002), is expressed in a small subpopulation of type C cells (Aguirre et al., 2004; Hack et al., 2004, 2005). In the developing spinal cord of Olig1/2-1compound knock-out mutant mice, the absence of Olig function leads putative motor neuron and oligodendrocyte progenitors to instead generate V2 interneurons and astrocytes (Zhou and Anderson, 2002), demonstrating that Olig activity is essential for the regulation of a binary glial cell fate choice (Rowitch, 2004). Furthermore, Olig2 acts as a repressor of astroglial (Gabay et al., 2003; Fukuda et al., 2004) and neuronal (Hack et al., 2005) differentiation. Intriguingly, we observed the expression of Olig2 in some GFAP-expressing cells, suggesting that Olig2 may begin to be expressed very early in the lineage. It is unlikely that Olig2 function is required for the transition of all SVZ astrocytes to type $\mathrm{C}$ cells because no obvious defect in olfac- 
tory bulb neuron development is observed in $18.5 \mathrm{~d}$ postcoitum Olig $2^{-/-}$null animals (K. Ligon and D. Rowitch, unpublished observations). However, our data raise the possibility that Olig2 expression is critical in a subset of type $\mathrm{C}$ cells that develop into oligodendrocytes. This conclusion is consistent with recent work overexpressing Olig2 in SVZ precursors (Buffo et al., 2005; Hack et al., 2005; Marshall et al., 2005). Although these results suggest that Olig2 expressing cells in the adult SVZ are progenitors of oligodendrocytes, we cannot exclude that these early progenitors could also generate other lineages. Note that it has recently been suggested that Olig2 may also be involved in the differentiation of astrocytes (Marshall et al., 2005).

We identified a population of PSA-NCAM ${ }^{+} / \mathrm{NG} 2^{+}$cells in the CC that express PDGFR $\alpha$ and Olig2 and have properties of immature migrating cells (Vaughn, 1969; Kakita and Goldman, 1999; Jennings et al., 2002). These young oligodendrocyte progenitors migrate individually or in small clusters but not in chains or ensheathed by glial tubes, as described for SVZ neuroblasts (Lois et al., 1996; Peretto et al., 1997). In contrast, migrating young oligodendrocytes are in intimate contact with myelinated axonal fibers. A similar close interaction between oligodendrocyte progenitors and axonal fibers has been shown in the optic nerve (Fulton et al., 1992). It has been suggested that young migrating oligodendrocytes originating in the neonatal SVZ disperse extensively in both radial and tangential planes (Suzuki and Goldman, 2003). This wide dispersion was not observed in our studies; oligodendrocytes generated in the adult SVZ were specifically found in the CC, the striatum, and fimbria fornix with little evidence of widespread rostrocaudal dispersion, suggesting that migration of oligodendrocyte progenitors born in the adult SVZ is limited to specific locations. A similar conclusion has been reached from developmental studies (Spassky et al., 2002). The affinity for axonal tracks within CC and striatum may explain the differences in dispersion observed between adults and neonates; these fibers may constrain tangential dispersion and explain the limited rostrocaudal distribution we observed.

Cells contained within the radial glia-astrocyte lineage serve as primary progenitors for new neurons in developing and adult brain (Alvarez-Buylla et al., 1990, 2001; Doetsch et al., 1999; Malatesta et al., 2000; Miyata et al., 2001; Noctor et al., 2001; Tamamaki et al., 2001; Merkle et al., 2005). Our results show that adult SVZ astrocytes generate oligodendrocytes. In primary cultures without the addition of growth factors or serum, single GFAP-expressing progenitors generate both oligodendrocytes and neurons. Only a small subpopulation of cells was multipotent in our assay (Fig. 6I). This could be attributable to the culture conditions we used, which may favor oligodendrocyte differentiation/survival, or could suggest that subpopulations of SVZ astrocytes are already committed for the generation of specific lineages. Our experimental protocol could also account for this result. For FACS isolation, we had to wait $36 \mathrm{~h}$ for accumulation of GFP in SVZ astrocytes after viral injections. By this time, many progenitors may have already moved along a particular lineage. Because our in vitro assay favors formation of differentiated clones, it could select for progenitors that are lineage restricted. Even under these stringent conditions, $\sim 11 \%$ of the plated cells that survived gave rise to both neurons and oligodendrocytes.

This work highlights the central role that SVZ type B cells, which were taken as fully differentiated astrocytes for many years, play in the generation of not only neurons but also of oligodendrocytes. Our experiments suggest that some SVZ type B cells can generate both lineages in vitro, but it remains to be determined in vivo whether single SVZ type B cells are multipotent. Under normal conditions, SVZ type B cells produce few oligodendrocytes compared with the large number of neurons generated. Interestingly, however, oligodendrogenesis can be significantly upregulated after a demyelinating lesion. It will be important to determine the precise stage in the progression from type $\mathrm{B}$ to type $\mathrm{C}$ cells at which progenitors become committed to a neuronal or glial lineage and how these decisions are regulated in response to environmental signals. The identification of SVZ type B cells as progenitors for young migrating oligodendrocyte precursors, parenchymal OPCs, and oligodendrocytes will help understand the normal turnover of this essential glial cell in the adult brain.

\section{References}

Aguirre AA, Chittajallu R, Belachew S, Gallo V (2004) NG2-expressing cells in the subventricular zone are type C-like cells and contribute to interneuron generation in the postnatal hippocampus. J Cell Biol 165:575-589.

Alvarez-Buylla A, Theelen M, Nottebohm F (1990) Proliferation "hot spots" in adult avian ventricular zone reveal radial cell division. Neuron 5:101-109.

Alvarez-Buylla A, Garcia-Verdugo JM, Tramontin AD (2001) A unified hypothesis on the lineage of neural stem cells. Nat Rev Neurosci 2:287-293.

Baumann N, Pham-Dinh D (2001) Biology of oligodendrocyte and myelin in the mammalian central nervous system. Physiol Rev 81:871-927.

Ben-Hur T, Rogister B, Murray K, Rougon G, Dubois-Dalcq M (1998) Growth and fate of PSA-NCAM ${ }^{+}$precursors of the postnatal brain. J Neurosci 18:5777-5788.

Blakemore WF (1972) Observations on oligodendrocyte degeneration, the resolution of status spongiosus and remyelination in cuprizone intoxication in mice. J Neurocytol 1:413-426.

Buffo A, Vosko MR, Erturk D, Hamann GF, Jucker M, Rowitch D, Gotz M (2005) Expression pattern of the transcription factor Olig2 in response to brain injuries: implications for neuronal repair. Proc Natl Acad Sci USA 102:18183-18188.

Butt AM (2004) Structure and function of oligodendrocytes. In: Neuroglia (Kettenmann H, ed), pp 36-47. New York: Oxford UP.

Carleton A, Petreanu LT, Lansford R, Alvarez-Buylla A, Lledo PM (2003) Becoming a new neuron in the adult olfactory bulb. Nat Neurosci 6:507-518.

Chari DM, Blakemore WF (2002) Efficient recolonisation of progenitordepleted areas of the CNS by adult oligodendrocyte progenitor cells. Glia 37:307-313.

Deloume JC, Raponi E, Gentil BJ, Bertacchi N, Marks A, Labourdette G, Baudier J (2004) Nuclear expression of S100b in oligodendrocyte progenitor cells correlates with differentiation toward the oligodendroglial lineage and modulates oligodendrocytes maturation. Mol Cell Neurosci 27:453-465.

Doetsch F, Alvarez-Buylla A (1996) Network of tangential pathways for neuronal migration in adult mammalian brain. Proc Natl Acad Sci USA 93:14895-14900.

Doetsch F, Garcia-Verdugo JM, Alvarez-Buylla A (1997) Cellular composition and three-dimensional organization of the subventricular germinal zone in the adult mammalian brain. J Neurosci 17:5046-5061.

Doetsch F, Caille I, Lim DA, Garcia-Verdugo JM, Alvarez-Buylla A (1999) Subventricular zone astrocytes are neural stem cells in the adult mammalian brain. Cell 97:703-716.

Doetsch F, Petreanu L, Caille I, Garcia-Verdugo JM, Alvarez-Buylla A (2002) EGF converts transit-amplifying neurogenic precursors in the adult brain into multipotent stem cells. Neuron 36:1021-1034.

Fancy SP, Zhao C, Franklin RJ (2004) Increased expression of Nkx2.2 and Olig2 identifies reactive oligodendrocyte progenitor cells responding to demyelination in the adult CNS. Mol Cell Neurosci 27:247-254.

Fukuda S, Kondo T, Takebayashi H, Taga T (2004) Negative regulatory effect of an oligodendrocytic bHLH factor Olig2 on the astrocytic differentiation pathway. Cell Death Differ 11:196-202.

Fulton BP, Burne JF, Raff MC (1992) Visualization of O-2A progenitor cells in developing and adult rat optic nerve by quisqualate-stimulated cobalt uptake. J Neurosci 12:4816-4833.

Gabay L, Lowell S, Rubin LL, Anderson DJ (2003) Deregulation of dorso- 
ventral patterning by FGF confers trilineage differentiation capacity on CNS stem cells in vitro. Neuron 40:485-499.

Gensert JM, Goldman JE (1997) Endogenous progenitors remyelinate demyelinated axons in the adult CNS. Neuron 19:197-203.

Gritti A, Parati EA, Cova L, Frolichsthal P, Galli R, Wanke E, Faravelli L, Morassutti DJ, Roisen F, Nickel DD, Vescovi AL (1996) Multipotential stem cells from the adult mouse brain proliferate and self-renew in response to basic fibroblast growth factor. J Neurosci 16:1091-1100.

Hack MA, Sugimori M, Lundberg C, Nakafuku M, Gotz M (2004) Regionalization and fate specification in neurospheres: the role of Olig2 and Pax6. Mol Cell Neurosci 25:664-678.

Hack MA, Saghatelyan A, de Chevigny A, Pfeifer A, Ashery-Padan R, Lledo PM, Gotz M (2005) Neuronal determinants of adult olfactory bulb neurogenesis. Nat Neurosci 8:865-872.

He W, Ingraham C, Rising L, Goderie S, Temple S (2001) Multipotent stem cells from the mouse basal forebrain contribute GABAergic neurons and oligodendrocytes to the cerebral cortex during embryogenesis. J Neurosci 21:8854-8862.

Holland EC, Varmus HE (1998) Basic fibroblast growth factor induces cell migration and proliferation after glia specific gene transfer in mice. Proc Natl Acad Sci USA 95:1218-1223.

Imura T, Kornblum HI, Sofroniew MV (2003) The predominant neural stem cell isolated from postnatal and adult forebrain but not early embryonic forebrain expresses GFAP. J Neurosci 23:2824-2832.

Jennings AR, Kirilak Y, Carroll WM (2002) In situ characterisation of oligodendrocyte progenitor cells in adult mammalian optic nerve. J Neurocytol 31:27-39.

Kakita A, Goldman JE (1999) Patterns and dynamics of SVZ cell migration in the postnatal forebrain: monitoring living progenitors in slice preparations. Neuron 23:461-472.

Kaplan MS, Hinds JW (1980) Gliogenesis of astrocytes and oligodendrocytes in the neocortical grey and white matter of the adult rat: electron microscopic analysis of light radioautographs. J Comp Neurol 193:711-727.

Kessaris N, Fogarty M, Lannarelli P, Grist M, Wegner M, Richardson WD (2006) Competing waves of oligodendrocytes in the forebrain and postnatal elimination of an embryonic lineage. Nat Neurosci 9:173-179.

Kondo T, Raff M (2000) Oligodendrocyte precursor cells reprogrammed to become multipotential CNS stem cells. Science 289:1754-1757.

Levison SW, Goldman JE (1993) Both oligodendrocytes and astrocytes develop from progenitors in the subventricular zone of postnatal rat forebrain. Neuron 10:201-212.

Ligon KL, Alberta JA, Kho A, Weiss J, Kwaan M, Nutt CL, Louis DN, Stiles CD, Rowitch DH (2004) The oligodendroglial lineage marker Olig2 is universally expressed in diffuse gliomas. J Neuropathol Exp Neurol 63:499-509.

Lim DA, Alvarez-Buylla A (1999) Interaction between astrocytes and adult subventricular zone precursors stimulates neurogenesis. Proc Natl Acad Sci USA 96:7526-7531.

Lois C, Alvarez-Buylla A (1994) Long-distance neuronal migration in the adult mammalian brain. Science 264:1145-1148.

Lois C, Garcia-Verdugo JM, Alvarez-Buylla A (1996) Chain migration of neuronal precursors. Science 271:978-981.

Lu QR, Sun T, Zhu Z, Ma N, Garcia M, Stiles CD, Rowitch DH (2002) Common developmental requirement for Olig function indicates a motor neuron/oligodendrocyte connection. Cell 109:75-86.

Lui Y, Rao MS (2004) Olig genes are expressed in a heterogeneous population of precursor cells in the developing spinal cord. Glia 45:67-74.

Luskin MB (1993) Restricted proliferation and migration of postnatally generated neurons derived from the forebrain subventricular zone. Neuron 11:173-189.

Malatesta P, Hartfuss E, Gotz M (2000) Isolation of radial glial cells by fluorescent-activated cell sorting reveals a neuronal lineage. Development 127:5253-5263.

McCarthy GF, Leblond CP (1988) Radioautographic evidence for slow astrocyte turnover and modest oligodendrocyte production in the corpus callosum of adult mice infused with $3 \mathrm{H}$-thymidine. J Comp Neurol 271:589-603.

Marshall CA, Novitch BG, Goldman JE (2005) Olig2 directs astrocyte and oligodendrocyte formation in postnatal subventricular zone cells. J Neurosci 25:7289-7298.

Merkle FT, Tramontin AD, Garcia-Verdugo JM, Alvarez-Buylla A (2004)
Radial glia give rise to adult neural stem cells in the subventricular zone. Proc Natl Acad Sci USA 101:17528-17532.

Miyata T, Kawaguchi A, Okano H, Ogawa H (2001) Asymmetric inheritance of radial glial fibers by cortical neurons. Neuron 31:727-741.

Morshead CM, Reynolds BA, Craig CG, McBurney MW, Staines WA, Morassutti D, Weiss S, van der Kooy D (1994) Neural stem cells in the adult mammalian forebrain: a relatively quiescent subpopulation of subependymal cells. Neuron 13:1071-1082.

Nait-Oumesmar B, Decker L, Lachapelle F, Avellana-Adalid V, Bachelin C, Baron-Van Evercooren A (1999) Progenitor cells of the adult mouse subventricular zone proliferate, migrate and differentiate into oligodendrocytes after demyelination. Eur J Neurosci 11:4357-4366.

Niehaus A, Stegmuller J, Diers-Fenger M, Trotter J (1999) Cell-surface glycoprotein of oligodendrocyte progenitors involved in migration. J Neurosci 19:4948-4961.

Nishiyama A, Lin XH, Giese N, Heldin CH, Stallcup WB (1996) Colocalization of NG2 protoglycan and PDGF alpha-receptor on O2A progenitor cells in the developing rat brain. J Neurosci Res 43:299-314.

Nishiyama H, Knopfel T, Endo S, Itohara S (2002) Glial protein S100B modulates long-term neuronal synaptic plasticity. Proc Natl Acad Sci USA 99:4037-4042.

Noctor SC, Flint AE, Weissman TA, Dammerman RS, Kriegstein AR (2001) Neurons derived from radial glial cells establish radial units in neocortex. Nature 409:714-720.

Olivier C, Cobos I, Perez Villegas EM, Spassky N, Zalc B, Martinez S, Thomas JL (2001) Monofocal origin of telencephalic oligodendrocytes in the anterior entopeduncular area of the chick embryo. Development 128:1757-1769.

Parent JM, von dem Bussche N, Lowenstein DH (2006) Prolonged seizures recruit caudal subventricular zone glial progenitors into the injured hippocampus. Hippocampus 16:321-328.

Parras CM, Galli R, Britz O, Soares S, Galichet C, Battiste J, Johnson JE, Nakafuku M, Vescovi A, Guillemot F (2004) Mash1 specifies neurons and oligodendrocytes in the postnatal brain. EMBO J 23:4495-4505.

Peretto P, Merighi A, Fasolo A, Bonfanti L (1997) Glial tubes in the rostral migratory stream of the adult rat. Brain Res Bull 42:9-21.

Peters A, Palay SL, Webster H (1991) The fine structure of the nervous system. New York: Oxford UP.

Petratos S, Gonzales MF, Azari MF, Marriott M, Minichiello RA, Shipham KA, Profyris C, Nicolaou A, Boyle K, Cheema SS, Kilpatrick TJ (2004) Expression of the low-affinity neurotrophin receptor, p75(NTR), is upregulated by oligodendroglial progenitors adjacent to the subventricular zone in response to demyelination. Glia 48:64-75.

Picard-Riera N, Decker L, Delarasse C, Goude K, Nait-Oumesmar B, Liblau R, Pham-Dinh D, Evercooren AB (2002) Experimental autoimmune encephalomyelitis mobilizes neural progenitors from the subventricular zone to undergo oligodendrogenesis in adult mice. Proc Natl Acad Sci USA 99:13211-13216.

Pluchino S, Quattrini A, Brambilla E, Gritti A, Salani G, Dina G, Galli R, Del Carro U, Amadio S, Bergami A, Furlan R, Comi G, Vescovi AL, Martino G (2003) Injection of adult neurospheres induces recovery in a chronic model of multiple sclerosis. Nature 422:688-694.

Polito A, Reynolds R (2005) NG2-expressing cells as oligodendrocyte progenitors in the normal and demyelinated adult central nervous system. J Anat 207:707-716.

Prineas JW, Connell F (1979) Remyelination in multiple sclerosis. Ann Neurol 5:22-31.

Pringle NP, Richardson WD (1993) A singularity of PDGF alpha-receptor expression in the dorsoventral axis of the neural tube may define the origin of the oligodendrocyte lineage. Development 117:525-533.

Qi Y, Stapp D, Qiu M (2002) Origin and molecular specification of oligodendrocytes in the telencephalon. Trends Neurosci 25:223-225.

Raff MC, Miller RH, Noble M (1983) A glial progenitor cell that develops in vitro into an astrocyte or an oligodendrocyte depending on culture medium. Nature 303:390-396.

Rao MS (1999) Multipotent and restricted precursors in the central nervous system. Anat Rec 257:137-148.

Reeves RH, Yao J, Crowley MR, Buck S, Zhang X, Yarowsky P, Gearhart JD, Hilt DC (1994) Astrocytosis and axonal proliferation in the hippocampus of S100b transgenic mice. Proc Natl Acad Sci USA 91:5359-5363.

Reynolds BA, Rietze RL (2005) Neural stem cells and neurospheres- reevaluating the relationship. Nat Methods 2:333-336. 
Richardson WD, Smith HK, Sun T, Pringle NP, Hall A, Woodruff R (2000) Oligodendrocyte lineage and the motor neuron connection. Glia 19:136-142.

Rowitch DH (2004) Glial specification in the vertebrate neural tube. Nat Rev Neurosci 5:409-419.

Santa-Olalla J, Baizabal JM, Fregoso M, del Carmen Cardenas M, Covarrubias L (2003) The in vivo positional identity gene expression code is not preserved in neural stem cells grown in culture. Eur J Neurosci 18:1073-1084.

Seri B, Herrera DG, Gritti A, Ferron S, Collado L, Vercovi A, Garcia-Verdugo JM, Alvarez-Buylla A (2006) Composition and organization of the SCZ: a large germinal layer containing neural stem cells in the adult mammalian brain. Cereb Cortex 16 [Suppl 1]:i103-i111.

Spassky N, Goujet-Zalc C, Parmantier E, Olivier C, Martinez S, Ivanova A, Ikenaka K, Macklin W, Cerruri I, Zalc B, Thomas JL (1998) Multiple restricted origin of oligodendrocytes. J Neurosci 18:8331-8343.

Spassky N, de Castro F, Le Bras B, Heydon K, Queraud-LeSaux F, BlochGallego E, Chedotal A, Zalc B, Thomas JL (2002) Directional guidance of oligodendroglial migration by class 3 semaphorins and netrin-1. J Neurosci 22:5992-6004.

Suzuki SO, Goldman JE (2003) Multiple cell populations in the early postnatal subventricular zone take distinct migratory pathways: a dynamic study of glial and neuronal progenitor migration. J Neurosci 23:4240-4250.

Tamamaki N, Nakamura K, Okamoto K, Kaneto T (2001) Radial glia is a progenitor of neocortical neurons in the developing cerebral cortex. Neurosci Res 41:51-60.

Thomas JL, Spassky N, Perez Villegas EM, Olivier C, Cobos I, Goujet-Zalc C, Martinez S, Zalc B (2000) Spatiotemporal development of oligodendrocytes in the embryonic brain. J Neurosci Res 59:471-476.
Timsit S, Martinez S, Allinquant B, Peyron F, Puelles L, Zalc B (1995) Oligodendrocytes originate in a restricted zone of the embryonic ventral neural tube defined by DM-20 mRNA expression. J Neurosci 15:1012-1024.

Vallstedt A, Klos JM, Ericson F (2004) Multiple dorsoventral origins of oligodendrocyte generation in the spinal cord and hindbrain. Neuron 45:55-67.

Vaughn JE (1969) An electron microscopic analysis of gliogenesis in the rat optic nerves. Z Zellforsch Mikrosk Anat 94:293-324.

Warf BC, Fok-Seang J, Miller RH (1991) Evidence for the ventral origin of oligodendrocyte precursors in the rat spinal cord. J Neurosci 11:2477-2488.

Weiss S, Dunne C, Hewson J, Wohl C, Wheatley M, Peterson AC, Reynolds BA (1996) Multipotent CNS stem cells are present in the adult mammalian spinal cord and ventricular neuroaxis. J Neurosci 16:7599-7609.

Wichterle H, Garcia-Verdugo JM, Alvarez-Buylla A (1997) Direct evidence for homotypic, glia-independent neuronal migration. Neuron 18:779-791.

Williams BP, Read J, Price J (1991) The generation of neurons and oligodendrocytes from a common precursor cell. Neuron 7:685-693.

Woodruff RH, Tekki-Kessaris N, Stiles CD, Rowitch DH, Richardson WD (2001) Oligodendrocyte development in the spinal cord and telencephalon: common themes and new perspectives. Int J Dev Neurosci 19:379-385.

Zhou Q, Wang S, Anderson DJ (2000) Identification of a novel family of oligodendrocyte lineage-specific basic helix-loop-helix transcription factors. Neuron 25:331-343.

Zhou Q, Anderson DJ (2002) The bHLH transcription factors OLIG2 and OLIG1 couple neuronal and glial subtype specification. Cell 109:61-73. 